\title{
Roof Movement and Failure Behavior When Mining Extra-Thick Coal Seams Using Upward Slicing Longwall-Roadway Cemented Backfill Technology
}

\author{
Xuejie Deng $\mathbb{D}^{1,2,3}$ Zongxuan Yuan, ${ }^{1}$ Lixin Lan, ${ }^{4}$ Benjamin de Wit, ${ }^{5}$ and Junwen Zhang $\mathbb{B D}^{1}$ \\ ${ }^{1}$ School of Energy and Mining Engineering, China University of Mining and Technology, Beijing 100083, China \\ ${ }^{2}$ State Key Laboratory of Coal Resources and Safe Mining, China University of Mining and Technology, Xuzhou 221116, China \\ ${ }^{3}$ Kailuan (Group) Limited Liability Corporation, Tangshan 063018, China \\ ${ }^{4}$ Department of Civil Engineering, Shanghai Jiao Tong University, Shanghai 200240, China \\ ${ }^{5}$ Norman B. Keevil Institute of Mining Engineering, University of British Columbia, Vancouver, BC V6T 1Z4, Canada \\ Correspondence should be addressed to Xuejie Deng; dengxj1989@gmail.com
}

Received 26 August 2019; Accepted 7 November 2019; Published 10 January 2020

Guest Editor: Qiusong Chen

Copyright (C) 2020 Xuejie Deng et al. This is an open access article distributed under the Creative Commons Attribution License, which permits unrestricted use, distribution, and reproduction in any medium, provided the original work is properly cited.

\begin{abstract}
A novel and environmental-friendly backfill mining method known as upward slicing longwall-roadway cemented backfill (USLCB) technology has recently been proposed and successfully applied in mines extracting extra-thick coal seams located under sensitive areas. This paper studies the effects USLCB had on roof movement and failure behavior using the mechanical analysis approach. The application of USLCB in the Gonggeyingzi Mine is taken as a case study with roof movement behavior being monitored over a single mining cycle, as well as over multiple mining cycles of different coal slices. In addition, backfill performance requirements to prevent roof failures where USLCB is implemented are studied. The results show that the deflection curves of the roof at the end of each mining cycle during mining the first and the six slices are symmetrical, but they change from asymmetrical to symmetrical during the mining progresses of the second slice to the fifth slice. The final state of roof movement after the first slice, and through to the fifth slice, displays an obvious "flat bottom" pattern in the middle of the deflection curve. The roof movement during the removal of the top slice is noticeably different from other slices. The results also show that the requirements of the elastic modulus, as well as the strength of the backfill, increase as the number of mined slices increases from 1 to 5 , but the requirements drop sharply for mining the top slice.
\end{abstract}

\section{Introduction}

The process of mining can be defined as economically recovering valuable minerals or other materials from the earth's crust either at the surface or underground $[1,2]$. Thick coal seams whose thickness is over $3.5 \mathrm{~m}$ comprise approximately half of the world's coal reserves and $70-80 \%$ of thick coal seams are extracted using underground mining methods $[3,4]$. In underground mining, the underground voids created as a result of extracting the valuable materials can present serious environmental challenges and are expected to be managed and remedied by filling them through a process known as backfilling technology [5-7]. Backfilling technology can control ground movement and prevent strata fracture and surface subsidence, as well as serve as an opportunity to dispose waste materials created during the extraction process $[8,9]$. An important backfill technology is cemented paste backfill [10-14], which is widely used across the industry for filling excavated stopes with a mixture of mine waste materials such as tailings, slags, and water [15-18]. Although cemented backfill has been widely used in industry because of its advantages, such as high backfilling ratio and flexible distribution systems $[19,20]$, the technology has been rarely applied in operations that are extracting extra-thick coal seams.

There are currently two main backfill mining methods used for extracting the majority of thick coal seams, including singlepass backfill mining and multislice backfill mining $[3,4,21,22]$. 
The major constraint with applying the single-pass backfill mining method in extra-thick coal seams is the limiting factor of the maximum mining height $[23,24]$. The multislice backfill mining method can provide a viable alternative to the previously stated methods for mining extra-thick coal seams as the backfill can support the overlying strata and prevent fractures and failures from developing $[25,26]$.

A novel and environmental-friendly mining and backfilling method known as upward slicing longwall-roadway cemented backfill (USLCB) technology to be proposed by Deng et al. and was initially published in 2017 [14]. The technical principles of the USLCB are shown in Figure 1 and described as follows [14]. The cemented backfill is prepared in a backfill plant at the surface and is transported underground to stopes through a network of backfilling pipelines [7, 27-29]. The extra-thick coal seam is divided into several slices with the deepest slice being mined first and the resulting void being filled with backfill material [30, 31]. Once the backfill material hardens $[32,33]$, it is used as a floor to facilitate the mining of the subsequent overlying slices as the entire coal seam is mined out progressively from bottom to top. The general longwall mining roadway system, including the preparation of roadways and gateways, is constructed prior to mining each slice. The roadheader is used to excavate crosscuts from the headgate to the tailgate, and after one crosscut is driven, it is filled with cemented backfill while the next crosscut is driven concurrently. A mining cycle contains 7 mining steps, and the mining sequence has been shown in Figure 2. After a mining cycle is finished, the coal pillar between first and second backfilling sections is totally mined out. The driving of crosscuts and the backfilling processes are repeated until the entire slice is mined out and backfilled.

The USLCB technology was applied to extract an extrathick coal seam with a thickness of 21 meters located under aquifers to protect the water, and it achieved positive application results [14]. However, although USLCB has indicated it can be a successful technology, the roof movement and failure behavior of USLCB need to be studied further. In this paper, a mechanical analysis approach is used to study roof movement behavior in mining extra-thick coal seams using USLCB technology. The application of this technology in the Gonggeyingzi Coal Mine is taken as a case study, with the roof movement behavior monitored and analyzed over a single mining cycle, over multiple mining cycles, and within each pass to excavate the different slices. In addition, the performance requirements of backfill material to prevent roof failures during the mining process of USLCB are calculated.

\section{The Roof Movement of Each Slice in the Mining Process of USLCB}

A mechanical analysis approach [34-36] is used to study the roof movement characteristics during the mining of each slice when extracting an extra-thick coal seam using USLCB technology. Nonhomogeneous elastic foundation beam models are developed in which the roof during the USLCB mining process is simplified as a beam. The mining process of USLCB is also considered in the mechanical models. It should be noted that the term roof is used to refer to different things. It refers to the stratum above the coal seam during the mining of the top slice. However, during the mining of the bottom slices, the roof refers to the remaining coal located above the extracted slice.

The coal body, backfilling body, and the combination of coal and backfilling are sectionally simplified as nonhomogeneous elastic foundations in the mechanical models [37-39]. According to the specific conditions of mining the extra-thick coal seam using USLCB technology, two mechanical models are established: a mechanical model for mining the first slice, located at the bottom, and another mechanical model for mining the remaining overlying slices.

\subsection{The Roof Movement Behavior of the First Slice}

2.1.1. The Mechanical Model of Mining the First Slice. The process of USLCB technology is that mined-out space is immediately filled with backfill material so that overlying strata are supported by the backfilling body and the coal pillars. The foundation structure of mining the first slice is shown in Figure 2. Therein, $L_{s}$ represents the total length of the mining area; $L$ is the length of each mining cycle; $n$ is the number of completed mining cycles; $n L$ is the length of mined range; $n_{s}$ represents the individual steps within the mining cycle; $a$ represents the width of each excavation step; $l_{1}$ and $l_{3}$ denote the width of first and second backfilling sections in a mining cycle, respectively; $l_{2}$ is the width of the coal pillar between the first and second backfilling sections in a mining cycle; and $l_{4}$ is the width of the coal pillar after the second backfilling section in a mining cycle.

During the mining cycling, the values of $l_{1}, l_{2}, l_{3}$, and $l_{4}$ are constantly changing as the mining and backfilling operations undertaken; however, the sum of these lengths is fixed, as shown in the following equation:

$$
L=l_{1}+l_{2}+l_{3}+l_{4} \text {. }
$$

There are 7 excavation steps in each mining cycle, so the value of $n_{s}$ is from 1 to 7 . The sizes of the crosscuts, pillars, and backfilling areas represented by the values $l_{1}, l_{2}, l_{3}$, and $l_{4}$ change as each step of the mining cycle is completed, and how these values change with each step of the mining cycle is summarized in Table 1.

The mechanical model of mining the first slice is shown in Figure 3, in which the elastic foundation beam is divided into 5 sections. Therein, $L_{0}$ and $L_{4}$ represent the range of the stress-concentrated area in the boundary pillars; $L_{1}$ is the range from the left mining limit boundary to the first coal pillar which means the width of past mining cycles plus the width of the first backfilling section in current mining cycle; $L_{2}$ is the width of the coal pillar between the first and second backfilling sections in present mining cycle; and $L_{3}$ represents the width of the second backfilling section in present mining cycle which begins after the first coal pillar and ends at the second coal pillar. 

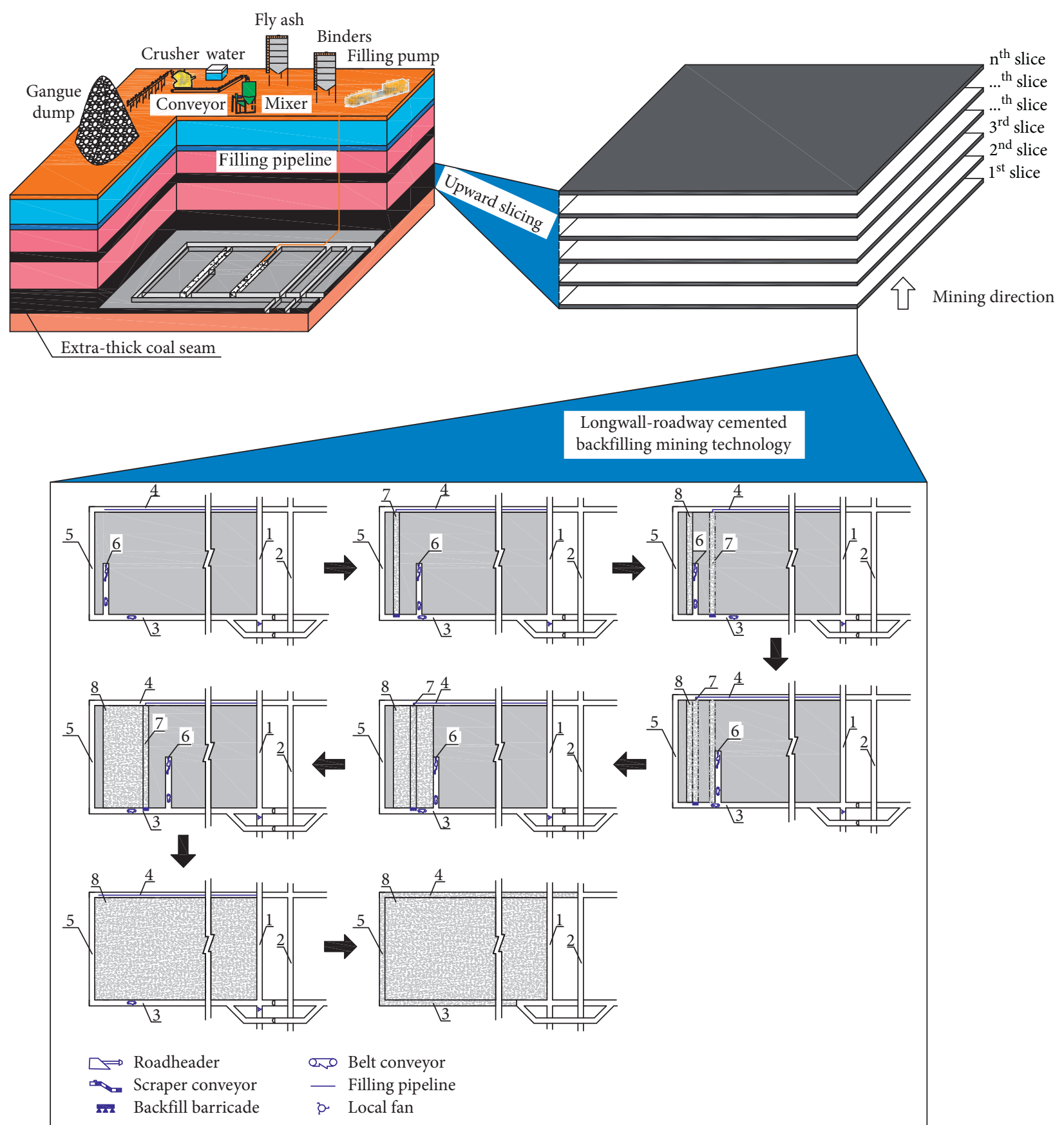

FIGURE 1: The technical principles of USLCB [14]. (1) Haulage rise; (2): rail rise; (3) headgate; (4) tailgate; (5) boundary crosscut; (6) mining working face; (7) backfilling working face; (8) backfilled body.

The parametric correspondence between the mechanical model of USLCB and the mining process of USLCB is shown in the following equation:

$$
\left\{\begin{array}{l}
L_{1}=n L+l_{1}, \\
L_{2}=l_{2}, \\
L_{3}=l_{3} .
\end{array}\right.
$$

2.1.2. The Mechanical Analysis of Roof Deflection during the Mining of the First Slice. Taking the point $\mathrm{O}$ of the beam as the origin, a coordinate system is established with the $X$-axis as the direction of mining and the $Y$-axis as the vertically downward direction. These axes are shown in Figure 3. Therein, $k_{c}$ and $k_{g}$ are the elastic foundation coefficients of coal and the backfilling body, respectively. The deflection calculation process of the beam is shown as follows:

(1) Section $L_{0}:-L_{0}-L_{1} \leq x \leq-L_{1}$

When $-L_{0}-L_{1} \leq x \leq-L_{1}$, the differential equation for deflection of the roof is shown in the following equation: 


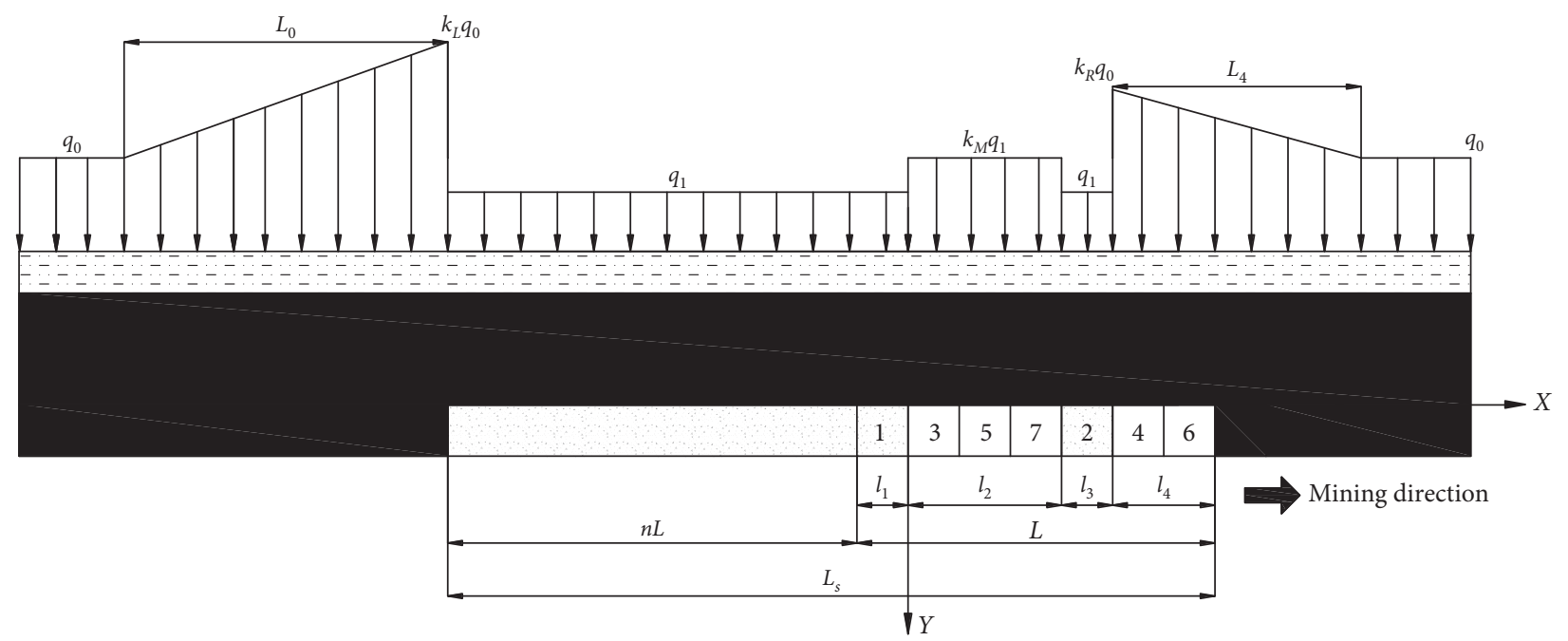

FIgURE 2: Diagram of the foundation structure for mining the first slice.

TABLE 1: The foundation structure of different excavation steps in a mining cycle.

\begin{tabular}{lcccc}
\hline$n_{s}$ & $l_{1}$ & $l_{2}$ & $l_{3}$ & \\
\hline 1 & $a$ & $3 a$ & 0 & \\
2 & $a$ & $3 a$ & $a$ & \\
3 & $2 a$ & $2 a$ & $2 a$ & \\
4 & $2 a$ & $2 a$ & $2 a$ & \\
5 & $3 a$ & $a$ & $3 a$ & \\
6 & $3 a$ & $a$ & $3 a$ & \\
7 & $4 a$ & 0 & $a$ & \\
\hline
\end{tabular}

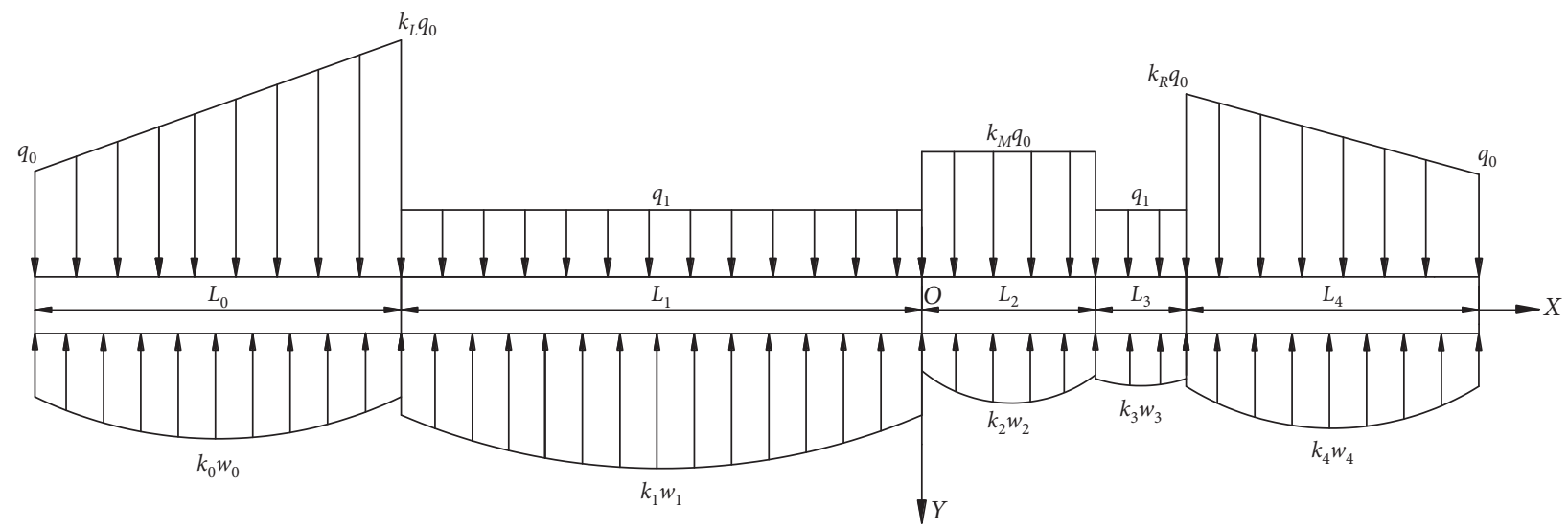

Figure 3: Mechanical model of mining first slice.

$$
E I \frac{d^{4} w_{0}(x)}{d x^{4}}+k_{0} w_{0}(x)=q_{1}(x)
$$

The load on the coal pillar can be expressed as follows:

$$
q_{1}(x)=\frac{\left(k_{l}-1\right) q_{0}}{L_{0}} x+k_{l} q_{0}+\frac{L_{1}\left(k_{l}-1\right) q_{0}}{L_{0}},
$$

where $k_{l}$ is the dimensionless stress concentration factor.
The deflection of the roof section $L_{0}$ is shown in the following equation:

$$
\begin{aligned}
w_{0}(x)= & e^{\alpha x}\left(A_{0} \cos (\alpha x)+B_{0} \sin (\alpha x)\right)+e^{-\alpha x}\left(C_{0} \cos (\alpha x)\right. \\
& \left.+D_{0} \sin (\alpha x)\right)+\frac{q_{1}(x)}{k_{0}},
\end{aligned}
$$

where $\alpha=\sqrt[4]{k_{0} / 4 E I}=\sqrt[4]{k_{c} / 4 E I}$ is the characteristic coefficient, in which $k_{0}=k_{c}$ is the elastic foundation 
coefficient of coal body, $\mathrm{N} / \mathrm{m}^{3} ; E$ is the elastic modulus of the roof, $\mathrm{Pa}$; and $I$ is the moment of inertia of the roof section, $\mathrm{m}^{4}$.

As " $x$ " tends towards negative infinity, the deflection of the roof is constant. The roof can be considered as a semi-infinite body, and this allows equation (5) to be simplified as follows:

$$
\begin{aligned}
w_{0}(x)= & e^{\alpha x}\left(A_{0} \cos (\alpha x)+B_{0} \sin (\alpha x)\right) \\
& +\frac{1}{k_{0}}\left[\frac{\left(k_{l}-1\right) q_{0}}{L_{0}} x+k_{l} q_{0}+\frac{L_{1}\left(k_{l}-1\right) q_{0}}{L_{0}}\right] .
\end{aligned}
$$

(2) Section $L_{1}:-L_{1} \leq x \leq 0$

When $-L_{1} \leq x \leq 0$, the differential equation for deflection of the roof is shown in the following equation:

$$
E I \frac{\mathrm{d}^{4} w_{1}(x)}{\mathrm{d} x^{4}}+k_{1} w_{1}(x)=q_{1}
$$

The deflection of the roof in section $L_{1}$ can be obtained and shown in the following equation:

$$
\begin{aligned}
w_{1}(x)= & e^{-\beta x}\left(A_{1} \cos (\beta x)+B_{1} \sin (\beta x)\right)+e^{\beta x}\left(C_{1} \cos (\beta x)\right. \\
& \left.+D_{1} \sin (\beta x)\right)+\frac{q_{1}}{k_{1}},
\end{aligned}
$$

where $\beta=\sqrt[4]{k_{1} / 4 E I}=\sqrt[4]{k_{g} / 4 E I}$ is the characteristic coefficient, in which $k_{1}=k_{g}$ is the elastic foundation coefficient of backfilling body, $\mathrm{N} / \mathrm{m}^{3}$.

(3) Section $L_{2}: 0<x \leq L_{2}$

When $0<x \leq L_{2}$, the differential equation for deflection of the roof is shown in the following equation:

$$
E I \frac{\mathrm{d}^{4} w_{2}(x)}{\mathrm{d} x^{4}}+k_{2} w_{2}(x)=k_{m} q_{0}
$$

where $k_{m}$ is the dimensionless stress concentration factor.

The deflection of the roof section $L_{2}$ can be obtained and shown in the following equation:

$$
\begin{aligned}
w_{2}(x)= & e^{-\alpha x}\left(A_{2} \cos (\alpha x)+B_{2} \sin (\alpha x)\right)+e^{\alpha x}\left(C_{2} \cos (\alpha x)\right. \\
& \left.+D_{2} \sin (\alpha x)\right)+\frac{k_{m} q_{0}}{k_{2}},
\end{aligned}
$$

where $k_{2}=k_{c}$ is the elastic foundation coefficient of coal body, $\mathrm{N} / \mathrm{m}^{3}$.

(4) Section $L_{3}: L_{2}<x \leq L_{2}+L_{3}$
When $L_{2}<x \leq L_{2}+L_{3}$, the differential equation for deflection of the roof is shown in the following equation:

$$
E I \frac{\mathrm{d}^{4} w_{3}(x)}{\mathrm{d} x^{4}}+k_{3} w_{3}(x)=q_{1} .
$$

The deflection of the roof in section $L_{3}$ can be expressed as follows:

$$
\begin{aligned}
w_{3}(x)= & e^{-\beta x}\left(A_{3} \cos (\beta x)+B_{3} \sin (\beta x)\right)+e^{\beta x}\left(C_{3} \cos (\beta x)\right. \\
& \left.+D_{3} \sin (\beta x)\right)+\frac{q_{1}}{k_{3}},
\end{aligned}
$$

where $k_{3}=k_{g}$ is the elastic foundation coefficient of backfilling body, $\mathrm{N} / \mathrm{m}^{3}$.

(5) Section $L_{4}: L_{2}+L_{3}<x \leq L_{2}+L_{3}+L_{4}$

When $L_{2}+L_{3}<x \leq L_{2}+L_{3}+L_{4}$, the differential equation for deflection of the roof is shown in the following equation:

$$
E I \frac{\mathrm{d}^{4} w_{4}(x)}{\mathrm{d} x^{4}}+k_{4} w_{4}(x)=q_{2}(x) .
$$

The load on the coal pillar can be expressed as follows:

$$
q_{2}(x)=\frac{\left(1-k_{r}\right) q_{0}}{L_{4}} x+k_{r} q_{0}+\frac{\left(L_{2}+L_{3}\right)\left(k_{r}-1\right) q_{0}}{L_{4}},
$$

where $k_{r}$ is the dimensionless stress concentration factor.

The deflection of the roof section $L_{4}$ is shown in the following equation:

$$
\begin{aligned}
w_{4}(x)= & e^{-\alpha x}\left(A_{4} \cos (\alpha x)+B_{4} \sin (\alpha x)\right)+e^{\alpha x}\left(C_{4} \cos (\alpha x)\right. \\
& \left.+D_{4} \sin (\alpha x)\right)+\frac{q_{2}(x)}{k_{4}},
\end{aligned}
$$

where $k_{4}=k_{c}$ is the elastic foundation coefficient of coal body, $\mathrm{N} / \mathrm{m}^{3}$.

As " $x$ " tends towards positive infinity, the deflection of the roof is constant. The roof can be considered as a semi-infinite body, and equation (15) can be simplified as follows:

$$
\begin{aligned}
w_{4}(x)= & e^{-\alpha x}\left(A_{4} \cos (\alpha x)+B_{4} \sin (\alpha x)\right) \\
& +\frac{1}{k_{4}}\left[\frac{\left(1-k_{r}\right) q_{0}}{L_{4}} x+k_{r} q_{0}+\frac{\left(L_{2}+L_{3}\right)\left(k_{r}-1\right) q_{0}}{L_{4}}\right] .
\end{aligned}
$$

The rotation $\theta(x)$, bending moment $M(x)$, and shearing force $Q(x)$ of an arbitrary cross section of the beam can be calculated by using the following equation: 


$$
\left\{\begin{array}{l}
\theta(x)=\frac{\mathrm{d} w(x)}{\mathrm{d} x} \\
M(x)=-E I \frac{\mathrm{d} w^{2}(x)}{\mathrm{d} x^{2}} \\
Q(x)=-E I \frac{\mathrm{d} w^{3}(x)}{\mathrm{d} x^{3}}
\end{array}\right.
$$

The boundary conditions and the continuity conditions of the mechanical model are shown in equation (18). All the parameters of the model can be solved according to the following conditions:

$$
\left\{\begin{array}{l}
w_{0}\left(-L_{1}\right)=w_{1}\left(-L_{1}\right) \\
\theta_{0}\left(-L_{1}\right)=\theta_{1}\left(-L_{1}\right) \\
M_{0}\left(-L_{1}\right)=M_{1}\left(-L_{1}\right) \\
Q_{0}\left(-L_{1}\right)=Q_{1}\left(-L_{1}\right) \\
w_{1}(0)=w_{2}(0) \\
\theta_{1}(0)=\theta_{2}(0) \\
M_{1}(0)=M_{2}(0) \\
Q_{1}(0)=Q_{2}(0) \\
w_{2}\left(L_{2}\right)=w_{3}\left(L_{2}\right) \\
\theta_{2}\left(L_{2}\right)=\theta_{3}\left(L_{2}\right) \\
M_{2}\left(L_{2}\right)=M_{3}\left(L_{2}\right) \\
Q_{2}\left(L_{2}\right)=Q_{3}\left(L_{2}\right) \\
w_{3}\left(L_{2}+L_{3}\right)=w_{4}\left(L_{2}+L_{3}\right) \\
\theta_{3}\left(L_{2}+L_{3}\right)=\theta_{4}\left(L_{2}+L_{3}\right) \\
M_{3}\left(L_{2}+L_{3}\right)=M_{4}\left(L_{2}+L_{3}\right) \\
Q_{3}\left(L_{2}+L_{3}\right)=Q_{4}\left(L_{2}+L_{3}\right)
\end{array}\right.
$$

\subsection{Roof Movement Behavior of the Remaining Upper Slices}

2.2.1. The Mechanical Model of Mining the Remaining Upper Slices. When mining the first slice using the USLCB method, the floor is composed of the undisturbed original ground. However, after the first slice is mined, and subsequently backfilled, the remaining upper slices will have the backfilling body serving as their floor for mining activities. Therefore, the foundation structure for mining these remaining slices will be different from the first slice, as shown in Figure 4.

The mechanical model of mining the remaining upper slices is shown in Figure 5, in which the elastic foundation beam is divided into 6 sections. Therein, $L_{5}$ and $L_{10}$ represent the range of the stress-concentrated area in the boundary pillars; $L_{6}$ is the range that is a combination of past mining cycles and the first backfilling section in current mining cycle; $L_{7}$ is the range of the coal pillar between the first and second backfilling sections in current mining cycle; $L_{8}$ represents the range of the second backfilling section in current mining cycle; and $L_{9}$ is the range of the coal pillar between the second backfilling sections in current mining cycle and the mining boundary of the previous slice.

The parametric correspondence between the mechanical model and applying USLCB to mining the remaining slices is shown in the following equation:

$$
\left\{\begin{array}{l}
L_{6}=n L+l_{1}, \\
L_{7}=l_{2}, \\
L_{8}=l_{3}, \\
L_{9}=L_{s}-\left(L_{6}+L_{7}+L_{8}\right) .
\end{array}\right.
$$

2.2.2. Mechanical Model for Calculating Deflection When Mining the Remaining Upper Slices. The mechanical model to determine deflection when mining the remaining upper slices that follow the mining of the first slice is similar to how deflection was calculated when mining the first slice, and the deflection calculation process of the beam is shown as follows:

(1) Section $L_{5}:-L_{5}-L_{6} \leq x \leq-L_{6}$ When $-L_{5}-L_{6} \leq x \leq-L_{6}$, the differential equation for deflection of the roof is shown in the following equation:

$$
E I \frac{\mathrm{d}^{4} w_{5}(x)}{\mathrm{d} x^{4}}+k_{5} w_{5}(x)=q_{3}(x) .
$$

The load on the coal pillar can be expressed as follows:

$$
q_{3}(x)=\frac{\left(l_{1}-1\right) q_{0}}{L_{5}} x+l_{1} q_{0}+\frac{L_{6}\left(l_{1}-1\right) q_{0}}{L_{5}}
$$

where $l_{1}$ is the dimensionless stress concentration factor.

The deflection of the roof in section $L_{5}$ is shown in the following equation:

$$
\begin{aligned}
w_{5}(x)= & e^{\alpha_{5} x}\left(A_{5} \cos \left(\alpha_{5} x\right)+B_{5} \sin \left(\alpha_{5} x\right)\right)+e^{-\alpha_{5} x} \\
& \cdot\left(C_{5} \cos \left(\alpha_{5} x\right)+D_{5} \sin \left(\alpha_{5} x\right)\right)+\frac{q_{3}(x)}{k_{5}}
\end{aligned}
$$

where $\alpha_{5}=\sqrt[4]{k_{5} / 4 E I}$ is the characteristic coefficient, in which $k_{5}=k_{c} / i(i=2, \ldots, 6)$ is the elastic foundation coefficient of coal body, $\mathrm{N} / \mathrm{m}^{3} ; E$ is the elastic modulus of the roof, $\mathrm{Pa}$; and $I$ is the moment of inertia of the roof section, $\mathrm{m}^{4}$.

As " $x$ " tends towards negative infinity, the deflection of the roof is constant. The roof can be considered as a semi-infinite body, so $C_{5}=0$ and $D_{5}=0$, and equation (22) can be simplified as follows:

$$
\begin{aligned}
w_{5}(x)= & e^{\alpha_{5} x}\left(A_{5} \cos \left(\alpha_{5} x\right)+B_{5} \sin \left(\alpha_{5} x\right)\right) \\
& +\frac{1}{k_{5}}\left[\frac{\left(l_{1}-1\right) q_{0}}{L_{5}} x+l_{1} q_{0}+\frac{L_{6}\left(l_{1}-1\right) q_{0}}{L_{5}}\right] .
\end{aligned}
$$




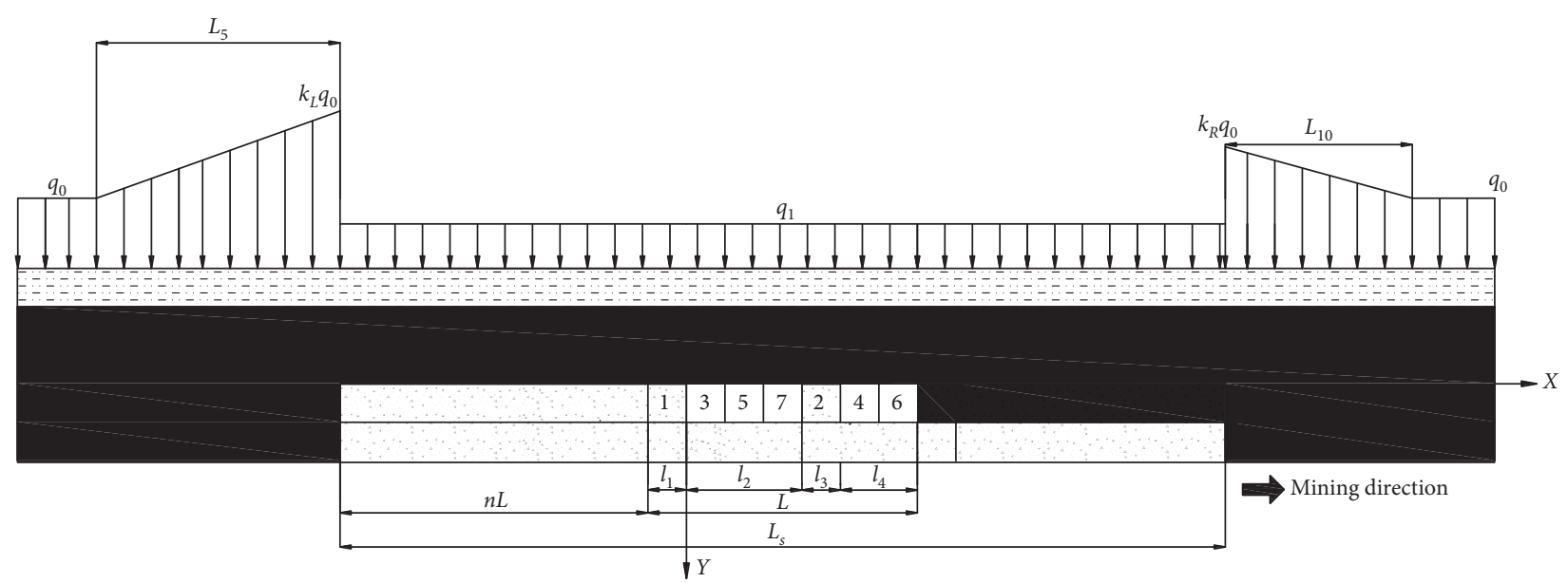

FIGURE 4: Foundation structure of mining the remaining upper slices.

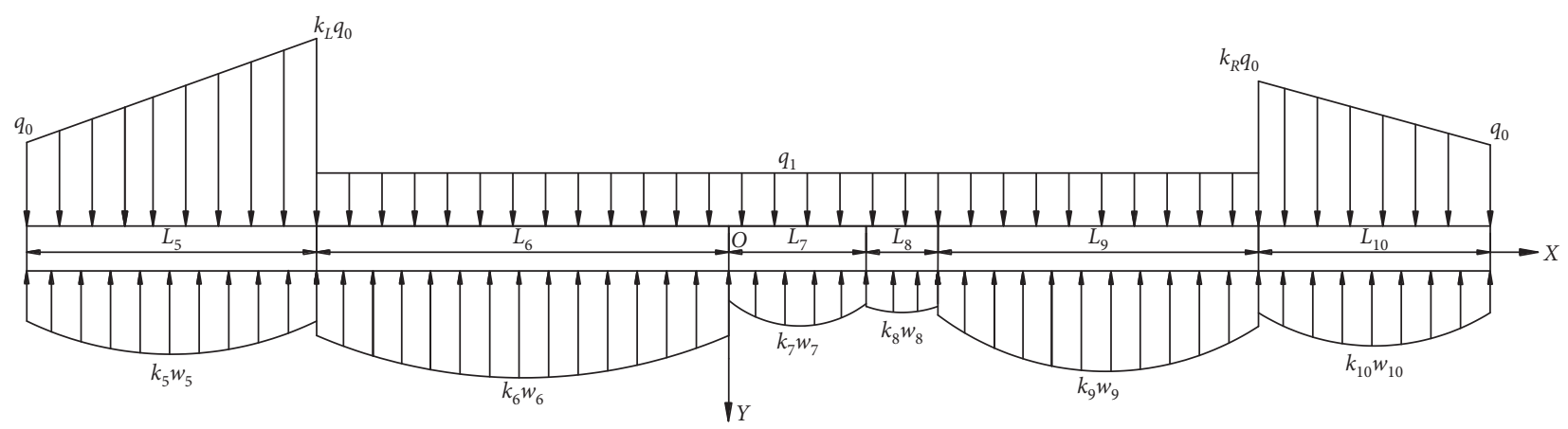

FIGURE 5: Mechanical model of mining the remaining upper slices.

(2) Section $L_{6}:-L_{6} \leq x \leq 0$

When $-L_{6} \leq x \leq 0$, the differential equation for deflection of the roof is shown in the following equation:

$$
E I \frac{\mathrm{d}^{4} w_{6}(x)}{\mathrm{d} x^{4}}+k_{6} w_{6}(x)=q_{2}
$$

The deflection of the roof in section $L_{6}$ can be expressed as follows:

$$
\begin{aligned}
w_{6}(x)= & e^{-\beta_{6} x}\left(A_{6} \cos \left(\beta_{6} x\right)+B_{6} \sin \left(\beta_{6} x\right)\right) \\
& +e^{\beta_{6} x}\left(C_{6} \cos \left(\beta_{6} x\right)+D_{6} \sin \left(\beta_{6} x\right)\right)+\frac{q_{2}}{k_{6}},
\end{aligned}
$$

where $\beta_{6}=\sqrt[4]{k_{6} / 4 E I}$ is the characteristic coefficient, in which $k_{6}=k_{g} / i(i=2, \ldots, 6)$ is the elastic foundation coefficient of the backfilling body, $\mathrm{N} / \mathrm{m}^{3}$.

(3) Section $L_{7}: 0<x \leq L_{7}$

When $0<x \leq L_{7}$, the differential equation for deflection of the roof is shown in the following equation:

$$
E I \frac{\mathrm{d}^{4} w_{7}(x)}{\mathrm{d} x^{4}}+k_{7} w_{7}(x)=q_{2}
$$

The deflection of the roof in section $L_{7}$ can be obtained and expressed as follows:

$$
\begin{aligned}
w_{7}(x)= & e^{-\beta_{7} x}\left(A_{7} \cos \left(\beta_{7} x\right)+B_{7} \sin \left(\beta_{7} x\right)\right) \\
& +e^{\beta_{7} x}\left(C_{7} \cos \left(\beta_{7} x\right)+D_{7} \sin \left(\beta_{7}\right)\right)+\frac{q_{2}}{k_{7}},
\end{aligned}
$$

where $\beta_{7}=\sqrt[4]{k_{7} / 4 E I}$ is the characteristic coefficient, in which $k_{7}=\left(k_{c} \cdot k_{g}\right) /\left((i-1) k_{c}+k_{g}\right)(i=2, \ldots, 6)$ is the elastic foundation coefficient for the combination of in situ coal and the backfilling body, N/m $\mathrm{m}^{3}$.

(4) Section $L_{8}: L_{7}<x \leq L_{7}+L_{8}$

When $L_{7}<x \leq L_{7}+L_{8}$, the differential equation for deflection of the roof is shown in the following equation:

$$
E I \frac{\mathrm{d}^{4} w_{8}(x)}{\mathrm{d} x^{4}}+k_{8} w_{8}(x)=q_{2} \text {. }
$$

The deflection of the roof in section $L_{8}$ can be expressed as follows:

$$
\begin{aligned}
w_{8}(x)= & e^{-\beta_{8} x}\left(A_{8} \cos \left(\beta_{8} x\right)+B_{8} \sin \left(\beta_{8} x\right)\right) \\
& +e^{\beta_{8} x}\left(C_{8} \cos \left(\beta_{8} x\right)+D_{8} \sin \left(\beta_{8} x\right)\right)+\frac{q_{2}}{k_{8}},
\end{aligned}
$$


where $\beta_{8}=\sqrt[4]{k_{8} / 4 E I}$ is the characteristic coefficient, in which $k_{8}=k_{g} / i(i=2, \ldots, 6)$ is the elastic foundation coefficient of the backfilling body, $\mathrm{N} / \mathrm{m}^{3}$.

(5) Section $L_{9}: L_{7}+L_{8}<x \leq L_{7}+L_{8}+L_{9}$

When $L_{7}+L_{8}<x \leq L_{7}+L_{8}+L_{9}$, the differential equation for deflection of the roof is shown in the following equation:

$$
E I \frac{\mathrm{d}^{4} w_{9}(x)}{\mathrm{d} x^{4}}+k_{9} w_{9}(x)=q_{2}
$$

The deflection of the roof section $L_{9}$ can be obtained and shown in the following equation:

$$
\begin{aligned}
w_{9}(x)= & e^{-\beta_{9} x}\left(A_{9} \cos \left(\beta_{9} x\right)+B_{9} \sin \left(\beta_{9} x\right)\right) \\
& +e^{\beta_{9} x}\left(C_{9} \cos \left(\beta_{9} x\right)+D_{9} \sin \left(\beta_{9} x\right)\right)+\frac{q_{2}}{k_{9}},
\end{aligned}
$$

where $\beta_{9}=\sqrt[4]{k_{9} / 4 E I}$ is the characteristic coefficient, in which $k_{9}=\left(k_{c} \cdot k_{g}\right) /\left((i-1) k_{c}+k_{g}\right)(i=2, \ldots, 6)$ is the elastic foundation coefficient of the combination of backfilling and coal body, $\mathrm{N} / \mathrm{m}^{3}$.

(6) Section $L_{10}: L_{7}+L_{8}+L_{9}<x \leq L_{7}+L_{8}+L_{9}+L_{10}$ When $L_{7}+L_{8}+L_{9}<x \leq L_{7}+L_{8}+L_{9}+L_{10}$, the differential equation for deflection of the roof is shown in the following equation:

$$
E I \frac{\mathrm{d}^{4} w_{10}(x)}{\mathrm{d} x^{4}}+k_{10} w_{10}(x)=q_{4}(x)
$$

The load on the coal pillar can be expressed as follows:

$$
q_{4}(x)=\frac{\left(1-l_{2}\right) q_{0}}{L_{10}} x+l_{2} q_{0}+\frac{\left(L_{7}+L_{8}+L_{10}\right)\left(l_{2}-1\right) q_{0}}{L_{10}},
$$

where $l_{2}$ is the dimensionless stress concentration factor.

The deflection of the roof section $L_{10}$ is shown in the following equation:

$$
\begin{aligned}
w_{10}(x)= & e^{-\alpha_{10} x}\left(A_{10} \cos \left(\alpha_{10} x\right)+B_{10} \sin \left(\alpha_{10} x\right)\right) \\
& +e^{\alpha_{10} x}\left(C_{10} \cos \left(\alpha_{10} x\right)+D_{10} \sin \left(\alpha_{10} x\right)\right)+\frac{q_{2}(x)}{k_{10}},
\end{aligned}
$$

where $\alpha_{10}=\sqrt[4]{k_{10} / 4 E I}$ is the characteristic coefficient, in which $k_{10}=k_{c} l i(i=2, \ldots, 6)$ is the elastic foundation coefficient of the coal body, $\mathrm{N} / \mathrm{m}^{3}$.

As " $x$ " tends towards positive infinity, the deflection of the roof is constant. The roof can be considered as a semi-infinite body, so $C_{10}=0$ and $D_{10}=0$, and equation (34) can be simplified as follows:

$$
\begin{aligned}
w_{10}(x)= & e^{-\alpha_{10} x}\left(A_{10} \cos \left(\alpha_{10} x\right)+B_{10} \sin \left(\alpha_{10} x\right)\right) \\
& +\frac{1}{k_{10}}\left[\frac{\left(1-l_{2}\right) q_{0}}{L_{10}} x+l_{2} q_{0}+\frac{\left(L_{7}+L_{8}+L_{10}\right)\left(l_{2}-1\right) q_{0}}{L_{10}}\right] .
\end{aligned}
$$

The boundary conditions and the continuity conditions of the mechanical model are shown in equation (36). All the parameters of the model can be solved according to the following conditions and equation (17):

$$
\left\{\begin{array}{l}
w_{5}\left(-L_{6}\right)=w_{6}\left(-L_{6}\right) \\
\theta_{5}\left(-L_{6}\right)=\theta_{6}\left(-L_{6}\right) \\
M_{5}\left(-L_{6}\right)=M_{6}\left(-L_{6}\right) \\
Q_{5}\left(-L_{6}\right)=Q_{6}\left(-L_{6}\right) \\
w_{6}(0)=w_{7}(0) \\
\theta_{6}(0)=\theta_{7}(0) \\
M_{6}(0)=M_{7}(0) \\
Q_{6}(0)=Q_{7}(0) \\
w_{7}\left(L_{7}\right)=w_{8}\left(L_{7}\right), \\
\theta_{7}\left(L_{7}\right)=\theta_{8}\left(L_{7}\right) \\
M_{7}\left(L_{7}\right)=M_{8}\left(L_{7}\right) \\
Q_{7}\left(L_{7}\right)=Q_{8}\left(L_{7}\right) \\
w_{8}\left(L_{7}+L_{8}\right)=w_{9}\left(L_{7}+L_{8}\right) \\
\theta_{8}\left(L_{7}+L_{8}\right)=\theta_{9}\left(L_{7}+L_{8}\right) \\
M_{8}\left(L_{7}+L_{8}\right)=M_{9}\left(L_{7}+L_{8}\right) \\
Q_{8}\left(L_{7}+L_{8}\right)=Q_{9}\left(L_{7}+L_{8}\right) \\
w_{9}\left(L_{7}+L_{8}+L_{9}\right)=w_{10}\left(L_{7}+L_{8}+L_{9}\right), \\
\theta_{9}\left(L_{7}+L_{8}+L_{9}\right)=\theta_{10}\left(L_{7}+L_{8}+L_{9}\right) \\
M_{9}\left(L_{7}+L_{8}+L_{9}\right)=M_{10}\left(L_{7}+L_{8}+L_{9}\right) \\
Q_{9}\left(L_{7}+L_{8}+L_{9}\right)=Q_{10}\left(L_{7}+L_{8}+L_{9}\right)
\end{array}\right.
$$

2.3. Roof Failure Criteria When Mining with USLCB Technology. The first strength theory, also known as the maximum tensile stress theory, is chosen as the failure criteria of the roof stratum. From the elastic foundation theory, the maximum tensile stress of the roof $\sigma_{\max }$ can be obtained from the maximum bending moment $M_{\max }$, which can be determined from the bending moment function $M(x)$, as shown in the following equation:

$$
\sigma_{\max }=\frac{6 \cdot|M|_{\max }}{h^{2}}
$$

where $h$ is the thickness of the roof, $m$.

Therefore, the failure criteria of the roof stratum can be expressed as follows:

$$
|M|_{\max } \leq \frac{h^{2} \cdot\left[\sigma_{\max }\right]}{6},
$$


where $\left[\sigma_{\max }\right]$ is the maximum allowable tensile stress of the roof, $\mathrm{MPa}$.

\section{Results and Discussion: A Case Study}

The USLCB mining technology was applied at the Gonggeyingzi Coal Mine to exploit a $21 \mathrm{~m}$ thick coal seam that is located $52.3 \mathrm{~m}$ under multiple aquifers. Specific details about the location and geological conditions of this mine, as well as the mining technology implemented there, have been published in a previous paper entitled "Upward slicing longwall-roadway cemented backfilling technology for mining an extra-thick coal seam located under aquifers: a case study" [14]. The entire $21 \mathrm{~m}$ coal seam in this mine is divided equally into 6 slices, where the thickness of each slice is $3.5 \mathrm{~m}$. The width of each excavation step is $5 \mathrm{~m}$, the vertical in situ stress $q_{0}$ is 2.5 MPa, and the elastic modulus of the backfilling body is $10 \mathrm{MPa}$. To study the roof movement of mining different slices of the extra-thick coal seam with USLCB technology, the specific parameters of each unique mining condition in the mine are substituted into the deflection equations seen throughout Section 2, and the results are shown as follows.

\subsection{Roof Movement Behavior inside a Single Mining Cycle.} The process of extracting the first slice during the first mining cycle is used to explain the changes and development of roof movement and deformation behavior inside a single mining cycle. The deflection curves of the roof after each mining step during this process are shown in Figure 6.

Figure 6 shows that, over a single mining cycle, the deflection curves of the roof can be divided into three types, i.e., the small range unimodal deflection curve of step 1-1-1, the bimodal deflection curves of steps 1-1-2 through to 1-1-6, and the large range unimodal deflection curve of step 1-1-7.

(1) The small range unimodal deflection curve occurs during the first step (step 1-1-1) of the mining cycle and signifies a mining range that is a single backfilling crosscut. The maximum subsidence of the roof is $11.02 \mathrm{~mm}$, and it appears in the middle of the deflection curve.

(2) Bimodal deflection curves occur through the second to the sixth mining steps (step 1-1-2 through to step 1-1-6) when there is a coal pillar in the middle of the mining range, which separates the active mining areas. When the mining range is symmetrical, the deflection curve is also symmetrically distributed. The two peaks appear above the two active parts of the mining range, respectively. The distance between two peaks varies between 25 and $30 \mathrm{~m}$, and the maximum subsidence of the roof increases from $11.26 \mathrm{~mm}$ to $13.75 \mathrm{~mm}$ gradually.

(3) The large range unimodal deflection curve occurs during the last mining step (step 1-1-7) when the mining range is seven backfilling crosscuts and coal pillar in the middle has been removed. Although the shape of the deflection curve is similar to the curve during the first mining step, the subsidence range of the roof is much larger compared to the first mining step. The maximum subsidence of the roof appears in the middle of the deflection curve and it significantly increases to $25.22 \mathrm{~mm}$.

3.2. Roof Movement Behavior during Multiple Mining Cycles. The first four mining cycles of each slice are used as examples to display different roof movement and deformation behavior during multiple mining cycles. The roof deflection curves of each slice at the end of the first four mining cycles are calculated and shown in Figure 7.

Figure 7(a) shows that all the roof deflection curves at the end of each mining cycle for the first slice all have a symmetrical distribution. As the number of mining cycles increases, both the range of roof subsidence and the maximum subsidence increase gradually. The maximum subsidence appears in the middle of the deflection curves. From the first to the fourth mining cycle of the first slice, the maximum subsidence of the roof is $25.22 \mathrm{~mm}, 45.48 \mathrm{~mm}, 52.86 \mathrm{~mm}$, and $53.00 \mathrm{~mm}$, respectively. After the third mining cycle of each slice, the maximum subsidence of the roof is almost achieved. Further subsidence after the third slice, resulting from an increase in the mining range, is relatively small, and only the range experiencing the near-maximum subsidence increases. After the fourth mining cycle, an obvious "flat bottom" pattern appeared in the middle of the deflection curve.

Figures 7(b)-7(e) show that the subsidence range of the roof does not significantly change during the mining of the second slice to the fifth slice, but the shape of the deflection curve changes significantly relative to the first slice. During the mining of the second slice to the fifth slice, the shape of the roof deflection curve changes from asymmetry (the end of the first three cycles) to symmetry (the end of the fourth cycle), and the maximum subsidence of the roof increases with its position moving gradually from the left side to the middle. Similar to the first slice, after the third mining cycle, there is a clear "flat bottom" pattern in the middle of the deflection curve of the roof, and the maximum subsidence is nearly achieved as there are no longer significant increases in subsidence with increases in the mining range.

Figure 7(f) shows that the deflection curve of the roof during the mining process of the sixth slice is obviously different from other slices. The main reason is that the roof for this final slice is the sandstone stratum overlying the entire extra-thick coal seam, whereas during the mining of previous slices the roof was overlying slices of coal that would eventually be extracted. After the fourth mining cycle is completed, the "flat bottom" pattern in the middle of the roof deflection curve is not particularly obvious. From the first to the fourth mining cycle, the maximum subsidence of the roof occurring at the end of each cycle is $433.51 \mathrm{~mm}$, $480.56 \mathrm{~mm}, 510.58 \mathrm{~mm}$, and $514.57 \mathrm{~mm}$, respectively.

3.3. Comparing Roof Movement Behavior during the Mining of Different Slices. In order to compare the roof movement 

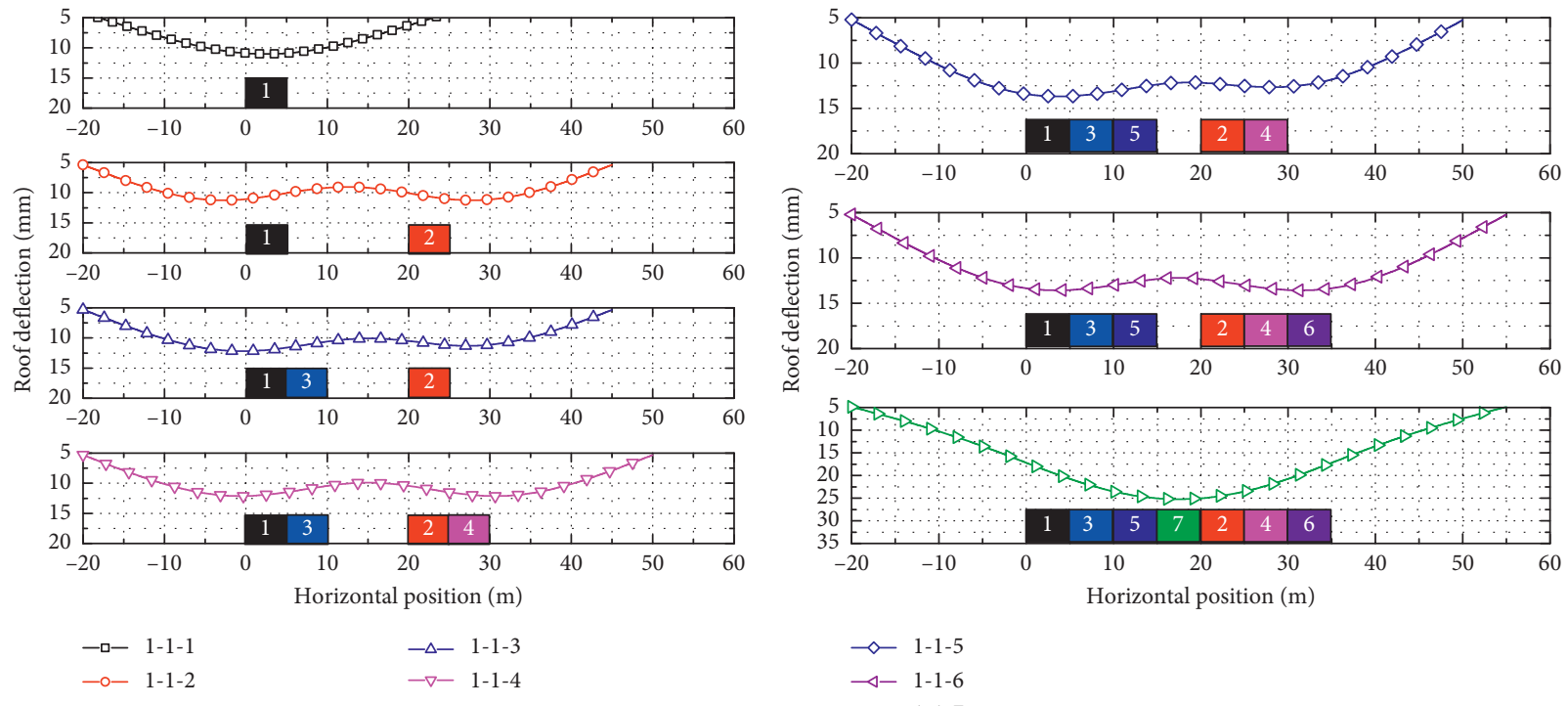

(a)

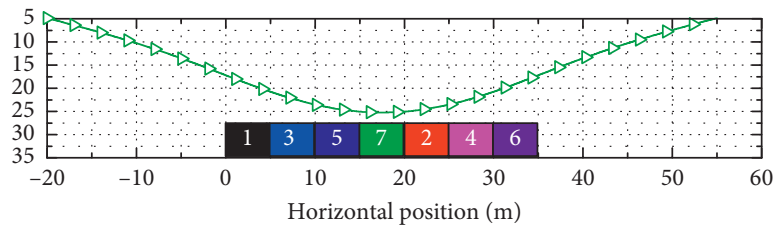

$\diamond 1-1-5$

$-4-1-1-6$

$\rightarrow \triangleright 1-1-7$

(b)

FiguRE 6: Deflection curves of the roof in the first mining cycle of the first slice. (a) 1-1-1 1-1-4 mining step and (b) 1-1-5 1-1-7 mining step.
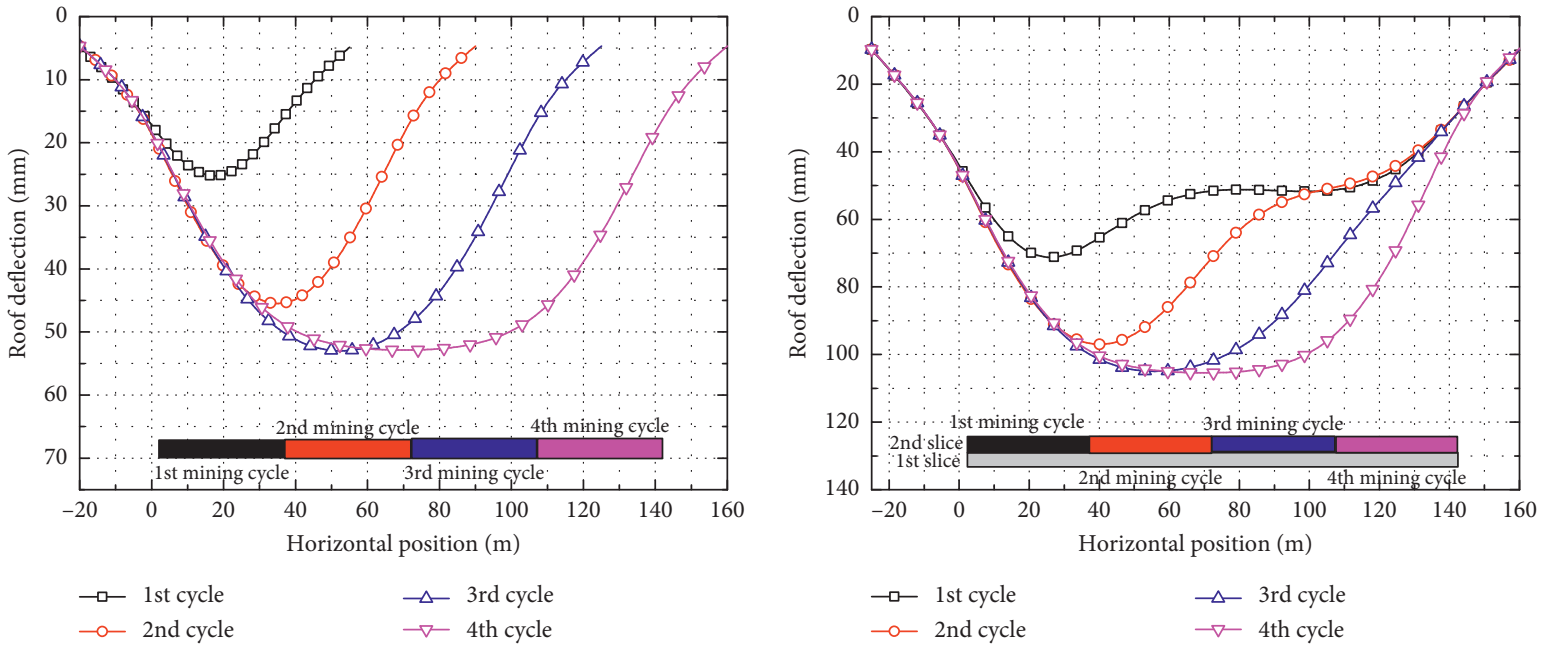

(a)

(b)
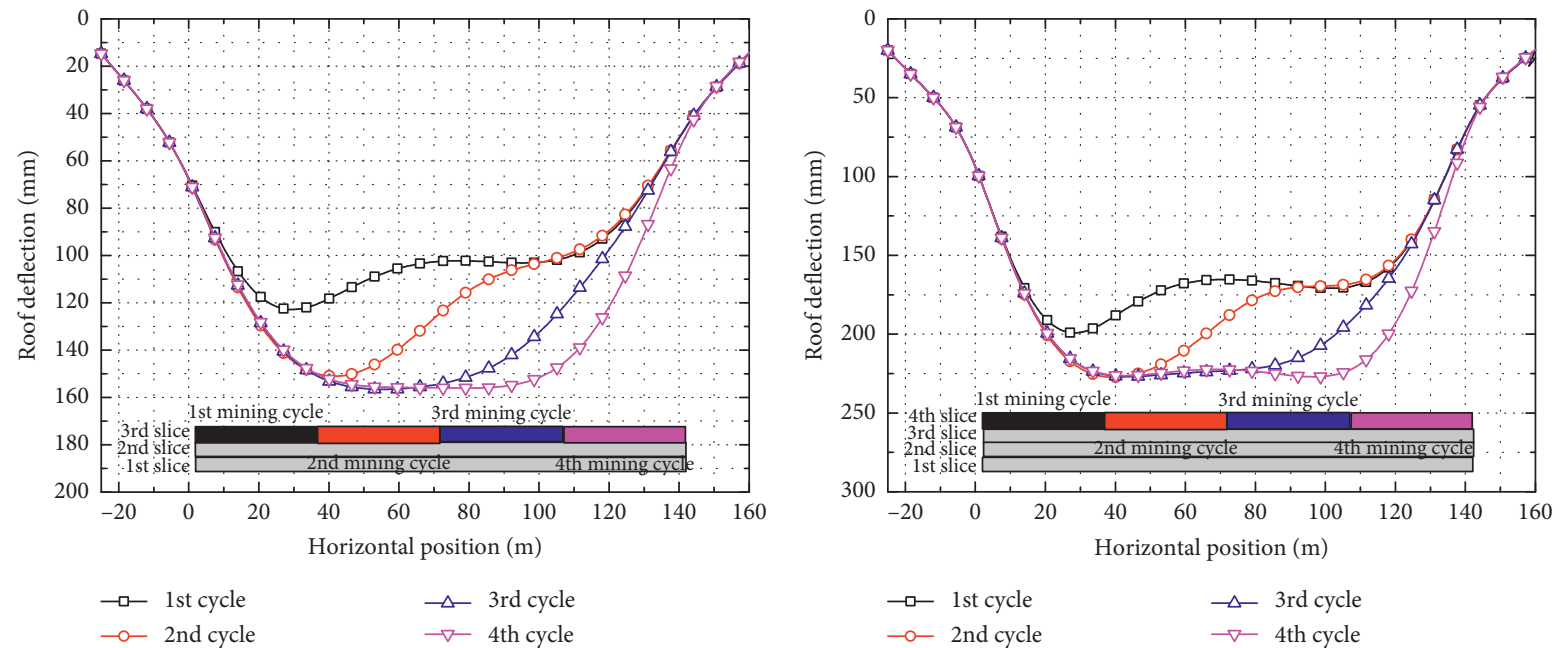

(c)

(d)

Figure 7: Continued. 


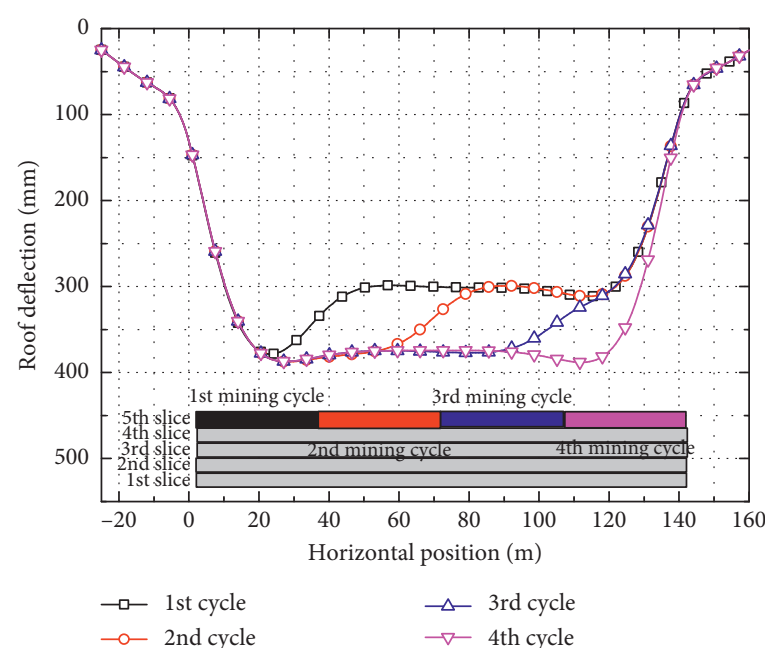

(e)

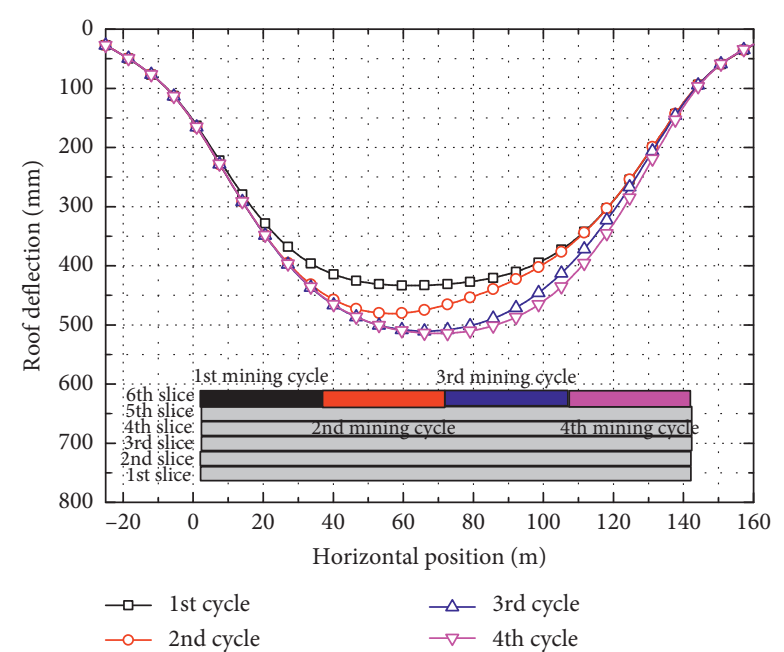

(f)

Figure 7: Deflection curves of the roof in different mining cycles of each slice: (a) first slice; (b) second slice; (c) third slice; (d) fourth slice; (e) fifth slice; (f) sixth slice.

behaviors seen when mining the different slices, the roof deflection curve during the sixth step in the first mining cycle is taken as a baseline example. It is compared with the roof deflection curves seen in the sixth step of subsequent slices. The results are plotted in Figure 8.

Figure 8 shows that, during the sixth step of the first mining cycle, the subsidence range of the first slice is much smaller than that of subsequent slices. An explanation is that mining the first slice is the initial disturbance to the stope, and mining subsequent slices are simply modifying an area that has already been disturbed with the roof being subjected to secondary and even numerous mining operations. The deflection curves of the roof in this sixth step of the first to fifth slices are bimodal curves, while it is a unimodal curve in the sixth slice. The reason for the occurrence of the bimodal curve is that there is a coal pillar in the middle of the mining range which can support the roof, but this supporting effect is relatively weaker during the mining of upper slices.

To compare the roof movement behavior of different slices during the mining process, the deflection curves of the roof after each mining cycle are calculated and plotted as shown in Figure 9.

Figure 9 shows that the deflection curve of the roof fluctuates less and is more symmetrical at the end of each mining cycle of the first and sixth slices, and the shape of the curve is noticeably different from other slices. The shape of the roof deflection curves is similar at the ends of each mining cycle of the second, third, fourth, and fifth slices, and as more slices are mined, increased roof subsidence is seen.

\subsection{The Requirement of Backfill Performance to Prevent Roof} Failure. The failure criteria of the roof are presented in Section 2.3. The allowable tensile stress and bending moment of the roof are different for each slice because of the different roof conditions in the mining process, as shown in Table 2.

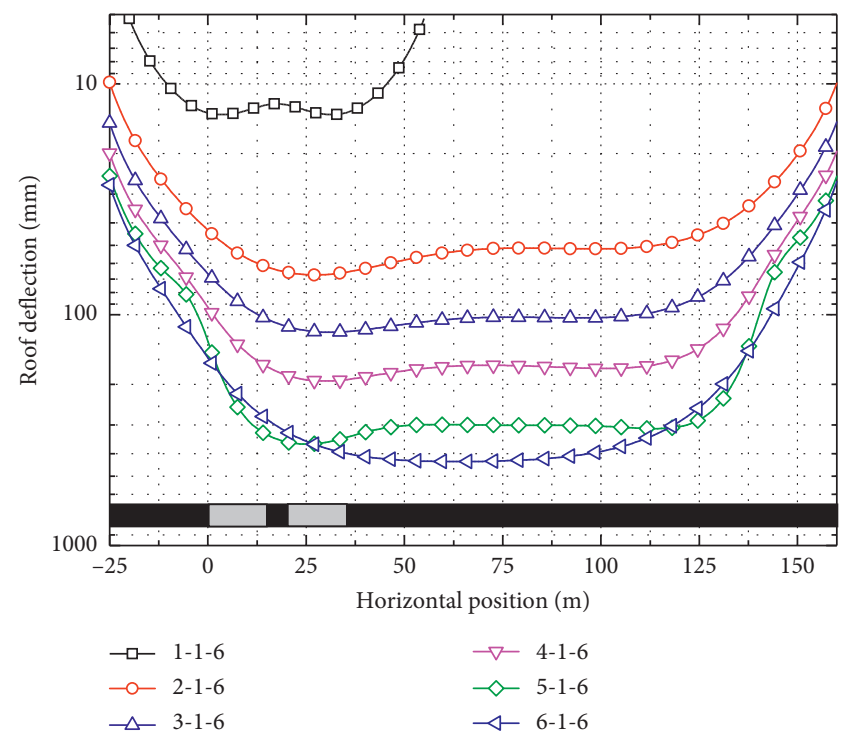

FIgURE 8: Deflection curves of the roof in the first to sixth mining step of each slice.

The elastic moduli for different types of backfilling materials are brought into the mechanical model to calculate the maximum bending moment of the roof during the mining process of each slice. Nonlinear regression is used to obtain a quantitative relationship between the elastic modulus of the backfilling material and the maximum bending moment of the roof for mining different slices. Combined with the allowable bending moment of the roof for each slice, the requirement for the elastic modulus of the backfilling material to ensure the roof does not break can be obtained. Then, the requirements for the strength of the backfilling material can be determined by measuring roof deflection and seeing when it reaches the critical failure state. 


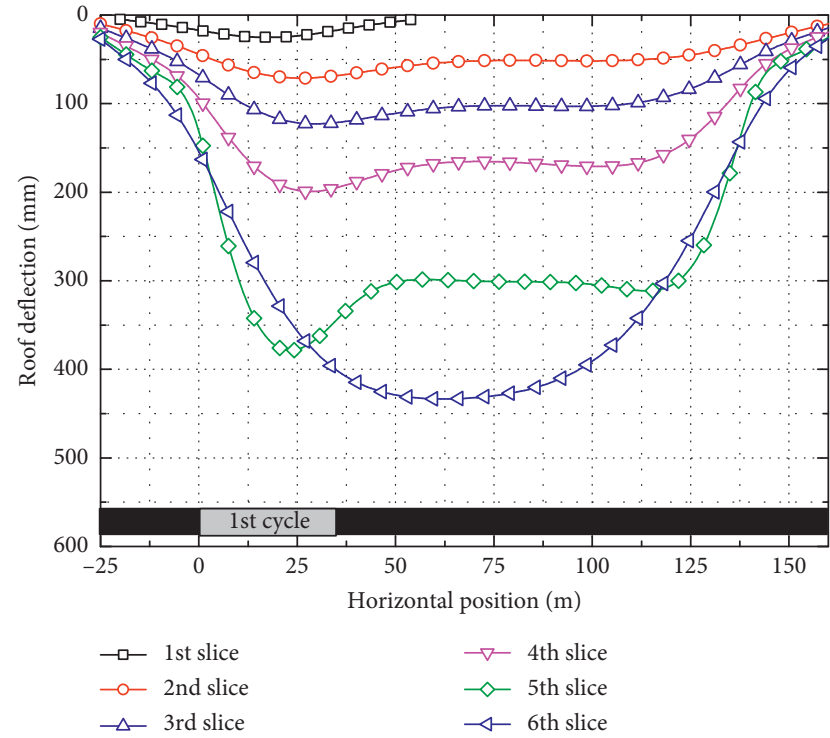

(a)

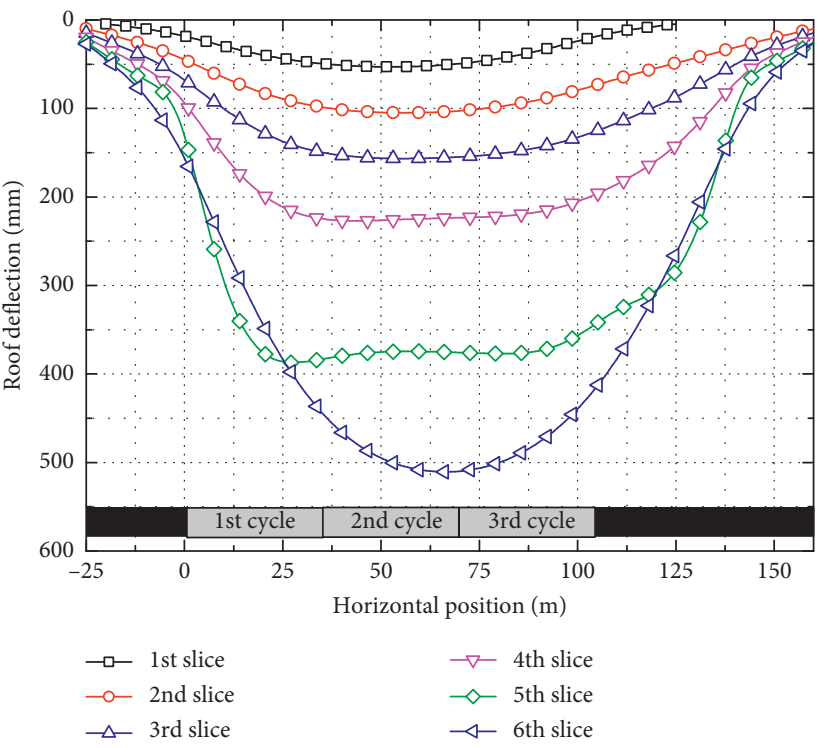

(c)

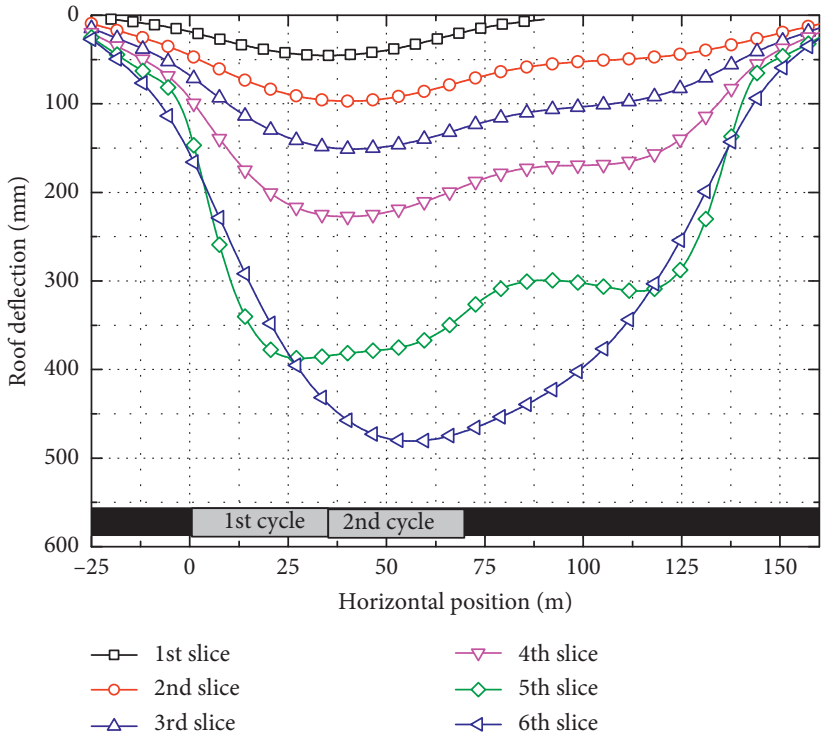

(b)

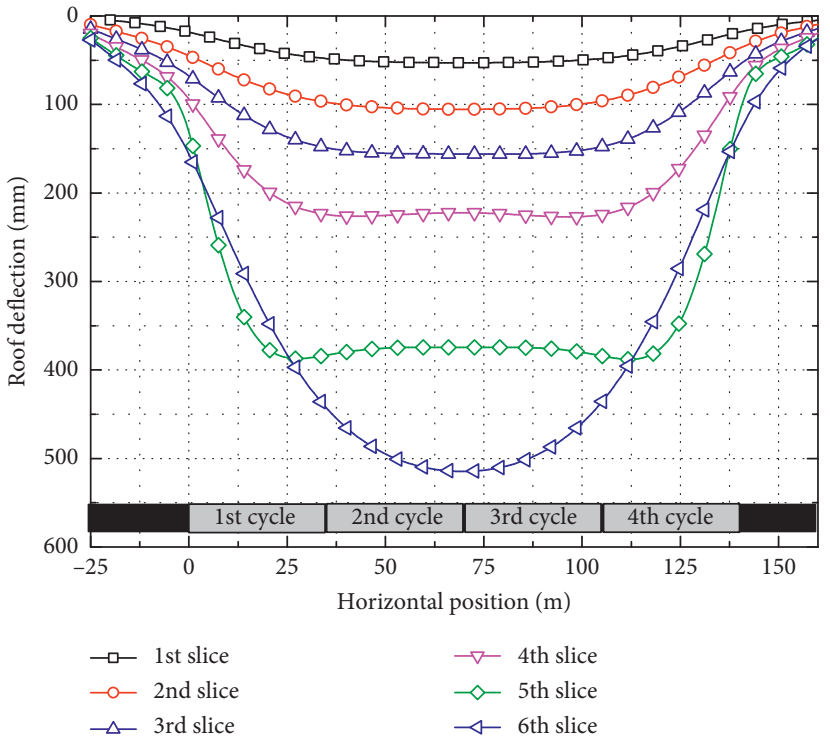

(d)

Figure 9: Deflection curves of the roof in different cycles during mining each slice: (a) first mining cycle; (b) second mining cycle; (c) third mining cycle; (d) fourth mining cycle.

TABLE 2: Allowable tensile stress and bending moment of the roof for different slices.

\begin{tabular}{|c|c|c|c|c|c|c|}
\hline Slice number & 1 & 2 & 3 & 4 & 5 & 6 \\
\hline Allowable tensile stress of the roof $(\mathrm{MPa})$ & 2.2 & 2.2 & 2.2 & 2.2 & 2.2 & 4 \\
\hline Allowable bending moment of the roof $(\mathrm{N} \cdot \mathrm{m})$ & $1.12 E 8$ & $7.19 E 7$ & $4.04 E 7$ & $1.80 E 7$ & $4.50 E 6$ & $4.00 E 8$ \\
\hline
\end{tabular}

The results of determining the performance requirement of cemented backfill are shown in Figure 10.

Figure 10(a) shows that the quantitative relationship between the maximum bending moment of the roof and the elastic modulus of the backfilling material can be described effectively by the power function. As the elastic modulus of the backfilling material increases, the maximum bending moment of the roof shows an exponential decay. Due to the different conditions of the roof, the maximum bending moment of the roof during the sixth slice is obviously larger than that of the other slices with the same backfilling material.

Figure 10(b) shows that the elastic modulus requirement for the backfill material increases from $2.84 \mathrm{MPa}$ to 29.44 MPa as the number of slices mined increases from 1 to 5 , but the requirement drops to $1.86 \mathrm{MPa}$ after the sixth slice is mined. The compressive strength requirement of the 


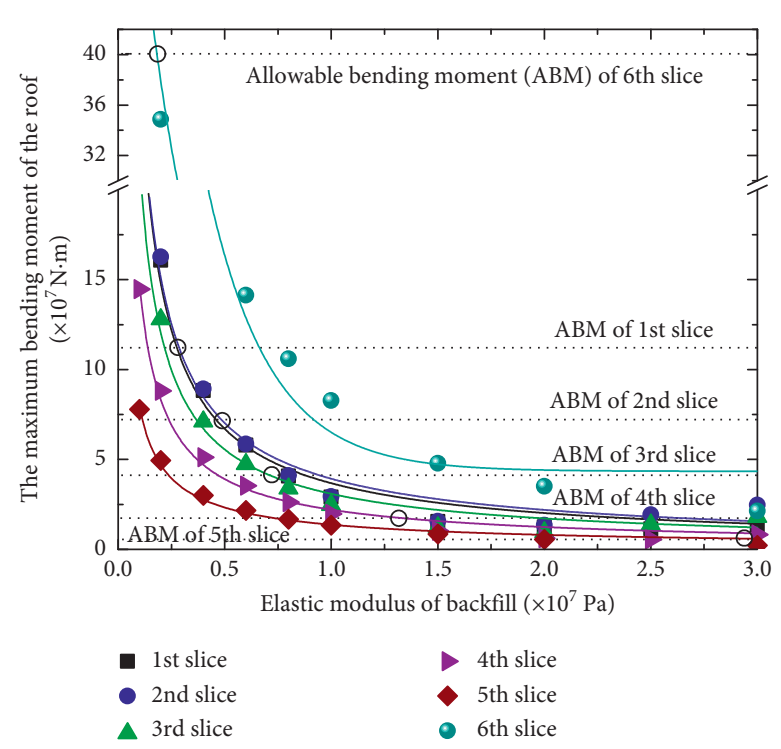

(a)

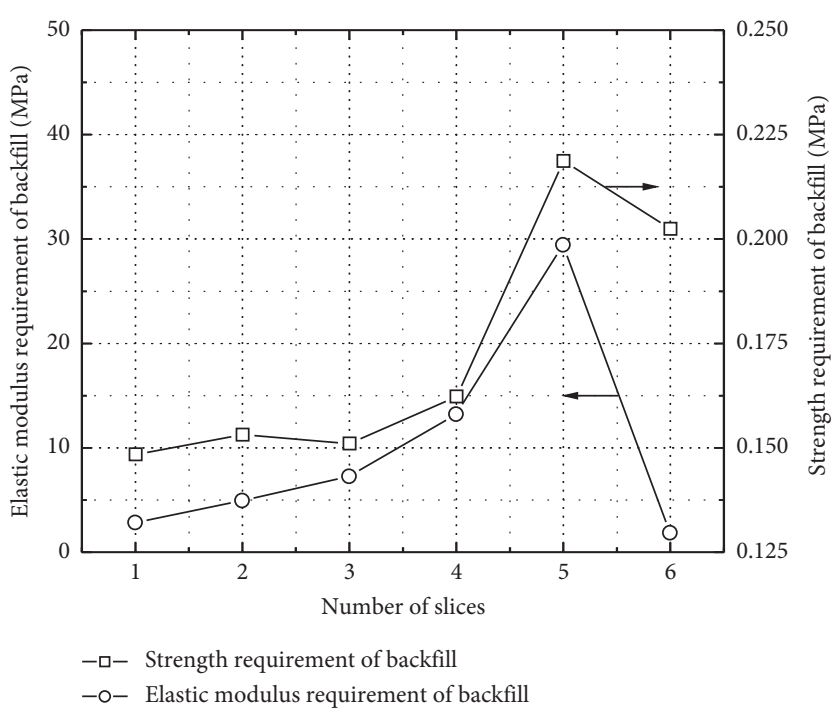

(b)

FIGURE 10: The performance requirement of cemented backfill: (a) the elastic modulus of backfill versus the maximum bending moment of the roof; (b) the elastic modulus and strength requirement of backfill for different slices.

backfill varies slightly within the range of 0.148 to $0.153 \mathrm{MPa}$ when the first three slices are mined. However, the strength requirement rapidly increases to $0.219 \mathrm{MPa}$ when the fifth slice is mined and decreases to $0.202 \mathrm{MPa}$ when the sixth slice is mined. The significant change in backfill requirement for the sixth slice shown in the calculation results is due to the different roof conditions compared to other slices. In this case, of all the slices, it is the fifth slice that requires the strongest backfill material for mining the entire extra-thick coal seam with USLCB technology. The performance requirement of cemented backfill calculated by this model is the final condition, which means that the final strength and elastic modulus of the cemented backfill should meet this requirement theoretically. Taking into account the safety margins, the performance of the cemented backfill with a curing time of 7 days can be selected to meet this requirement for the industry application.

\section{Conclusions}

In this paper, a mechanical analysis approach is used to study roof movement and roof control in mining extra-thick coal seam using USLCB technology. The main findings and conclusions are as follows:

(1) In a single mining cycle of the first slice, the deflection curves of the roof can be divided into three types, i.e., the small range unimodal deflection curve in the initial step, the bimodal deflection curves of the middle steps with two active areas, and the large range unimodal deflection curve in the final step when the support pillar is removed. The shape of the curve is significantly affected by the mined area.

(2) All of the roof deflection curves that occur at the end of each mining cycle during the extraction of the first slice are symmetrical in their distribution. Also, there is an obvious "flat bottom" pattern occurring in the middle of the deflection curve after the fourth mining cycle is completed.

(3) During the mining of the second slice to the end of the fifth slice, the shape of the roof deflection curve changes from asymmetrical to symmetrical. After the third mining cycle is completed during the mining of these slices, there is a clear "flat bottom" pattern in the middle of the roof deflection curve. The roof movement during the mining of the top slice is noticeably different from roof movement during the mining of other slices. This difference is due to that the roof lithology of the top slice is different from previous slices whose immediate roof is actually the remaining coal seam.

(4) The relationship between the maximum bending moment of the roof and the elastic modulus of the backfilling material can be well described by the power function. The requirements of the backfill material's elastic modulus and strength increase as the number of mined slices increases from 1 to 5 , but the requirements drop sharply when the sixth slice is mined.

\section{Data Availability}

The data used to support the findings of this study are included within the article.

\section{Conflicts of Interest}

The authors declare that they have no conflicts of interest.

\section{Acknowledgments}

This work was supported by the National Key R\&D Program of China (Grant no. 2018YFC0604701), National Natural 
Science Foundation of China (Youth Program) (Grant no. 51804308), the Research Fund of the State Key Laboratory of Coal Resources and Safe Mining, CUMT (Grant no. SKLCRSM18KF022), and the Natural Science Foundation of Heilongjiang Province of China (Grant no. LH2019E118). The authors would like to thank those researchers who have made great contributions to the project. Special thanks go to the Gonggeyingzi Coal Mine for providing everything for the field application studied in this research.

\section{References}

[1] A. Kesimal, E. Yilmaz, and B. Ercikdi, "Evaluation of paste backfill mixtures consisting of sulphide-rich mill tailings and varying cement contents," Cement and Concrete Research, vol. 34, no. 10, pp. 1817-1822, 2004.

[2] J. X. Zhang, X. J. Deng, X. Zhao, F. Ju, and B. Y. Li, "Effective control and performance measurement of solid waste backfill in coal mining," International Journal of Mining, Reclamation and Environment, vol. 31, no. 2, pp. 91-104, 2017.

[3] A. K. Ghose, "Underground methods of extraction of thick coal seams-a global survey," Mining Science and Technology, vol. 2, no. 1, pp. 17-32, 1984.

[4] B. Unver and N. E. Yasitli, "Modelling of strata movement with a special reference to caving mechanism in thick seam coal mining," International Journal of Coal Geology, vol. 66, no. 4, pp. 227-252, 2006.

[5] Y. Huang, J. Zhang, Q. Zhang, and S. Nie, "Backfilling technology of substituting waste and fly ash for coal underground in China coal mining area," Environmental Engineering \& Management Journal (EEMJ), vol. 10, 2011.

[6] X. Deng, J. Zhang, T. Kang, and X. Han, "Strata behavior in extra-thick coal seam mining with upward slicing backfilling technology," International Journal of Mining Science and Technology, vol. 26, no. 4, pp. 587-592, 2016.

[7] X. Deng, J. Zhang, B. Klein, N. Zhou, and B. deWit, "Experimental characterization of the influence of solid components on the rheological and mechanical properties of cemented paste backfill," International Journal of Mineral Processing, vol. 168, pp. 116-125, 2017.

[8] J. F. Archibald, J. L. Chew, and P. Lausch, "Use of ground waste glass and normal Portland cement mixtures for improving slurry and paste backfill support performance," CIM Bulletin, vol. 92, pp. 74-80, 1999.

[9] P. K. Senapati, B. K. Mishra, R. R. Barik, and D. P. Mohanty, "Evaluating the head loss of coal ash slurry pipelines at high solids concentrations using rheological data for mine backfilling," Energy Sources, Part A: Recovery, Utilization, and Environmental Effects, vol. 37, no. 14, pp. 1542-1549, 2015.

[10] L. Festugato, A. Fourie, and N. C. Consoli, "Cyclic shear response of fibre-reinforced cemented paste backfill," Géotechnique Letters, vol. 3, no. 1, pp. 5-12, 2013.

[11] E. Yilmaz, T. Belem, B. Bussière, M. Mbonimpa, and M. Benzaazoua, "Curing time effect on consolidation behaviour of cemented paste backfill containing different cement types and contents," Construction and Building Materials, vol. 75, pp. 99-111, 2015.

[12] A. Wu, Y. Wang, H. Wang, S. Yin, and X. Miao, "Coupled effects of cement type and water quality on the properties of cemented paste backfill," International Journal of Mineral Processing, vol. 143, pp. 65-71, 2015.

[13] B. D. Thompson, W. F. Bawden, and M. W. Grabinsky, "In situ measurements of cemented paste backfill at the Cayeli mine," Canadian Geotechnical Journal, vol. 49, no. 7, pp. 755-772, 2012.

[14] X. J. Deng, J. X. Zhang, N. Zhou, B. de Wit, and C. T. Wang, "Upward slicing longwall-roadway cemented backfilling technology for mining an extra-thick coal seam located under aquifers: a case study," Environmental Earth Sciences, vol. 76, no. 23, pp. 1-15, 2017.

[15] J. P. Doherty, A. Hasan, G. H. Suazo, and A. Fourie, "Investigation of some controllable factors that impact the stress state in cemented paste backfill," Canadian Geotechnical Journal, vol. 52, no. 12, pp. 1901-1912, 2015.

[16] F. Cihangir, B. Ercikdi, A. Kesimal, A. Turan, and H. Deveci, "Utilisation of alkali-activated blast furnace slag in paste backfill of high-sulphide mill tailings: effect of binder type and dosage," Minerals Engineering, vol. 30, pp. 33-43, 2012.

[17] M. Fall, M. Benzaazoua, and S. Ouellet, "Experimental characterization of the influence of tailings fineness and density on the quality of cemented paste backfill," Minerals Engineering, vol. 18, no. 1, pp. 41-44, 2005.

[18] A. Kesimai, E. Yilmaz, B. Ercikdi, I. Alp, M. Yumlu, and B. Ozdemir, "Laboratory testing of cemented paste backfill," Madencilik, vol. 41, no. 4, pp. 11-20, 2002.

[19] F. Sofrá and D. V. Boger, "Environmental rheology for waste minimisation in the minerals industry," Chemical Engineering Journal, vol. 86, no. 3, pp. 319-330, 2002.

[20] B. E. Wickland, G. W. Wilson, D. Wijewickreme, and B. Klein, "Design and evaluation of mixtures of mine waste rock and tailings," Canadian Geotechnical Journal, vol. 43, no. 9, pp. 928-945, 2006.

[21] P. K. Mandal, R. Singh, J. Maiti et al., "Underpinning-based simultaneous extraction of contiguous sections of a thick coal seam under weak and laminated parting," International Journal of Rock Mechanics and Mining Sciences, vol. 45, no. 1, pp. 11-28, 2008.

[22] J. Wang, B. Yu, H. Kang et al., "Key technologies and equipment for a fully mechanized top-coal caving operation with a large mining height at ultra-thick coal seams," International Journal of Coal Science \& Technology, vol. 2, no. 2, pp. 97-161, 2015.

[23] A. Vakili and B. K. Hebblewhite, "A new cavability assessment criterion for longwall top coal caving," International Journal of Rock Mechanics and Mining Sciences, vol. 47, no. 8, pp. 1317-1329, 2010.

[24] G. X. Xie, J. C. Chang, and K. Yang, "Investigations into stress shell characteristics of surrounding rock in fully mechanized top-coal caving face," International Journal of Rock Mechanics and Mining Sciences, vol. 46, no. 1, pp. 172-181, 2009.

[25] M. R. Islam, D. Hayashi, and A. B. M. Kamruzzaman, "Finite element modeling of stress distributions and problems for multi-slice longwall mining in Bangladesh, with special reference to the Barapukuria coal mine," International Journal of Coal Geology, vol. 78, no. 2, pp. 91-109, 2009.

[26] A. Majdi, F. P. Hassani, and M. Y. Nasiri, "Prediction of the height of destressed zone above the mined panel roof in longwall coal mining," International Journal of Coal Geology, vol. 98, pp. 62-72, 2012.

[27] X. Deng, B. Klein, L. Tong, and B. de Wit, "Experimental study on the rheological behavior of ultra-fine cemented backfill," Construction and Building Materials, vol. 158, pp. 985-994, 2018.

[28] Y. He, Q. Chen, C. Qi, Q. Zhang, and C. Xiao, "Lithium slag and fly ash-based binder for cemented fine tailings backfill," Journal of Environmental Management, vol. 248, Article ID 109282, 2019. 
[29] Y. Liu, Q. Zhang, Q. Chen, C. Qi, Z. Su, and Z. Huang, "Utilisation of water-washing pre-treated phosphogypsum for cemented paste backfill," Minerals, vol. 9, no. 3, p. 175, 2019.

[30] X. J. Deng, B. Klein, D. J. Hallbom, B. de Wit, and J. X. Zhang, "Influence of particle size on the basic and time-dependent rheological behaviors of cemented paste backfill," Journal of Materials Engineering and Performance, vol. 27, no. 7, pp. 3478-3487, 2018.

[31] X. J. Deng, B. Klein, J. X. Zhang, D. Hallbom, and B. de Wit, "Time-dependent rheological behaviour of cemented backfill mixture," International Journal of Mining, Reclamation and Environment, vol. 32, no. 3, pp. 145-162, 2018.

[32] Y. Feng, J. Kero, Q. Yang et al., "Mechanical activation of granulated copper slag and its influence on hydration heat and compressive strength of blended cement," Materials, vol. 12, no. 5, p. 772, 2019.

[33] Y. Feng, Q. Yang, Q. Chen et al., "Characterization and evaluation of the pozzolanic activity of granulated copper slag modified with CaO," Journal of Cleaner Production, vol. 232, pp. 1112-1120, 2019.

[34] M. Li, J. Zhang, and R. Gao, "Mechanical analysis of roof subsidence based on rheological properties of solid backfill materials," Tehnicki Vjesnik-Technical Gazette, vol. 25, no. 1, pp. 152-157, 2018.

[35] Q. Guo, G. Guo, X. Lv, W. Zhang, Y. Lin, and S. Qin, "Strata movement and surface subsidence prediction model of dense solid backfilling mining," Environmental Earth Sciences, vol. 75, no. 21, 2016.

[36] A. Vervoort, "Surface movement above an underground coal longwall mine after closure," Natural Hazards and Earth System Sciences Discussions, vol. 16, no. 9, pp. 2107-2121, 2016.

[37] V. Kajzar, R. Kukutsch, P. Waclawik, and J. Nemcik, "Innovative approach to monitoring coal pillar deformation and roof movement using 3D laser technology," Procedia Engineering, vol. 191, pp. 873-879, 2017.

[38] J. Ning, J. Wang, L. Jiang, N. Jiang, X. Liu, and J. Jiang, "Fracture analysis of double-layer hard and thick roof and the controlling effect on strata behavior: a case study," Engineering Failure Analysis, vol. 81, pp. 117-134, 2017.

[39] G. Song and S. Yang, "Investigation into strata behaviour and fractured zone height in a high-seam longwall coal mine," Journal of the Southern African Institute of Mining and Metallurgy, vol. 115, no. 8, pp. 781-788, 2015. 


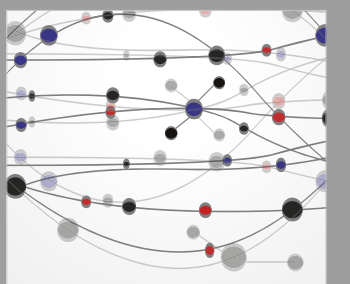

The Scientific World Journal
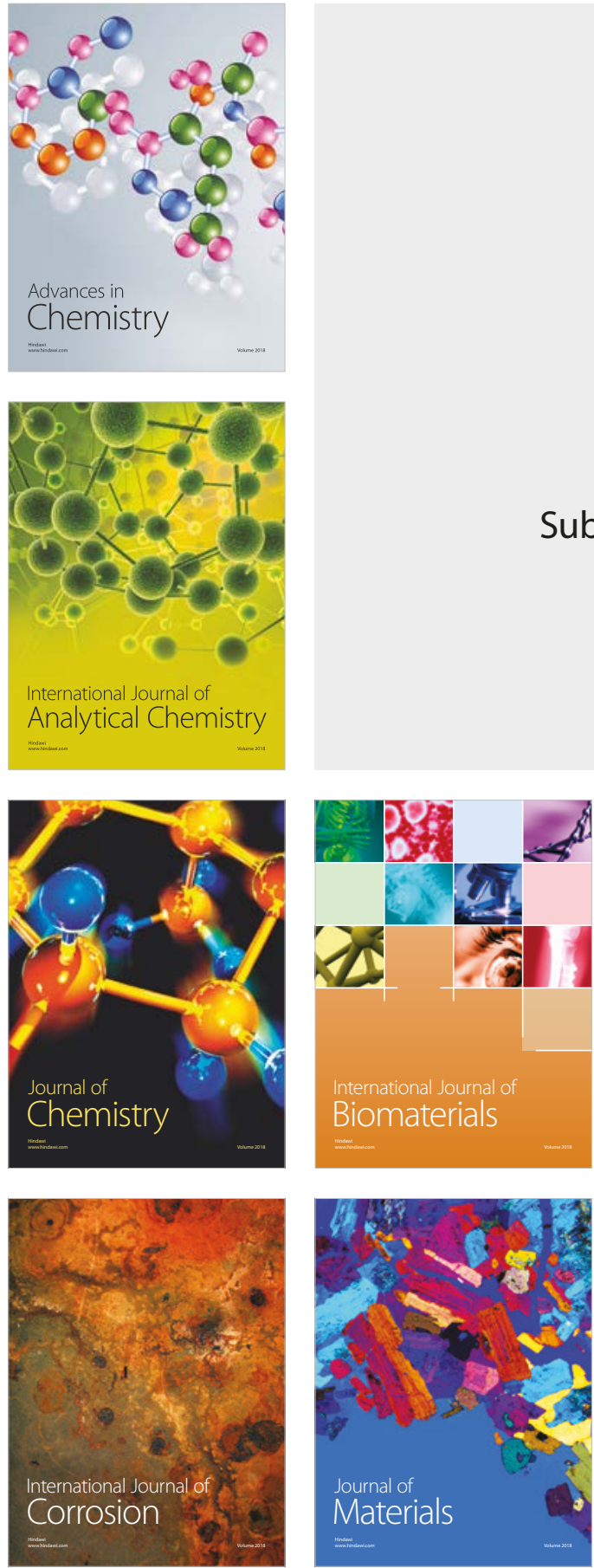

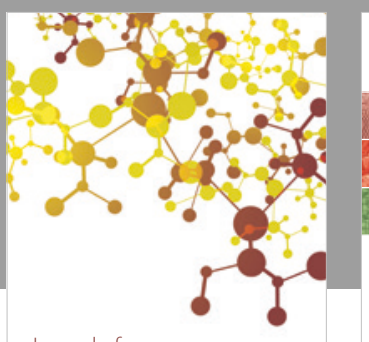

Journal of

Applied Chemistry
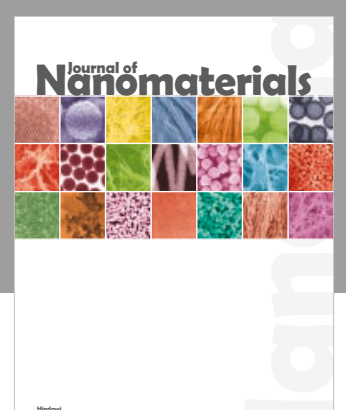

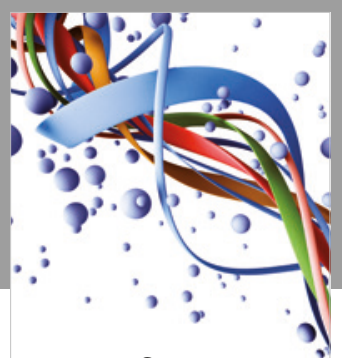

Scientifica

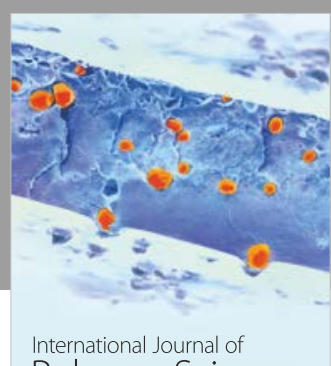

Polymer Science

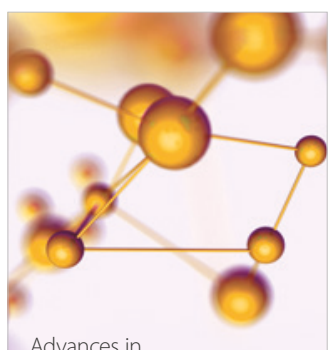

Physical Chemistry
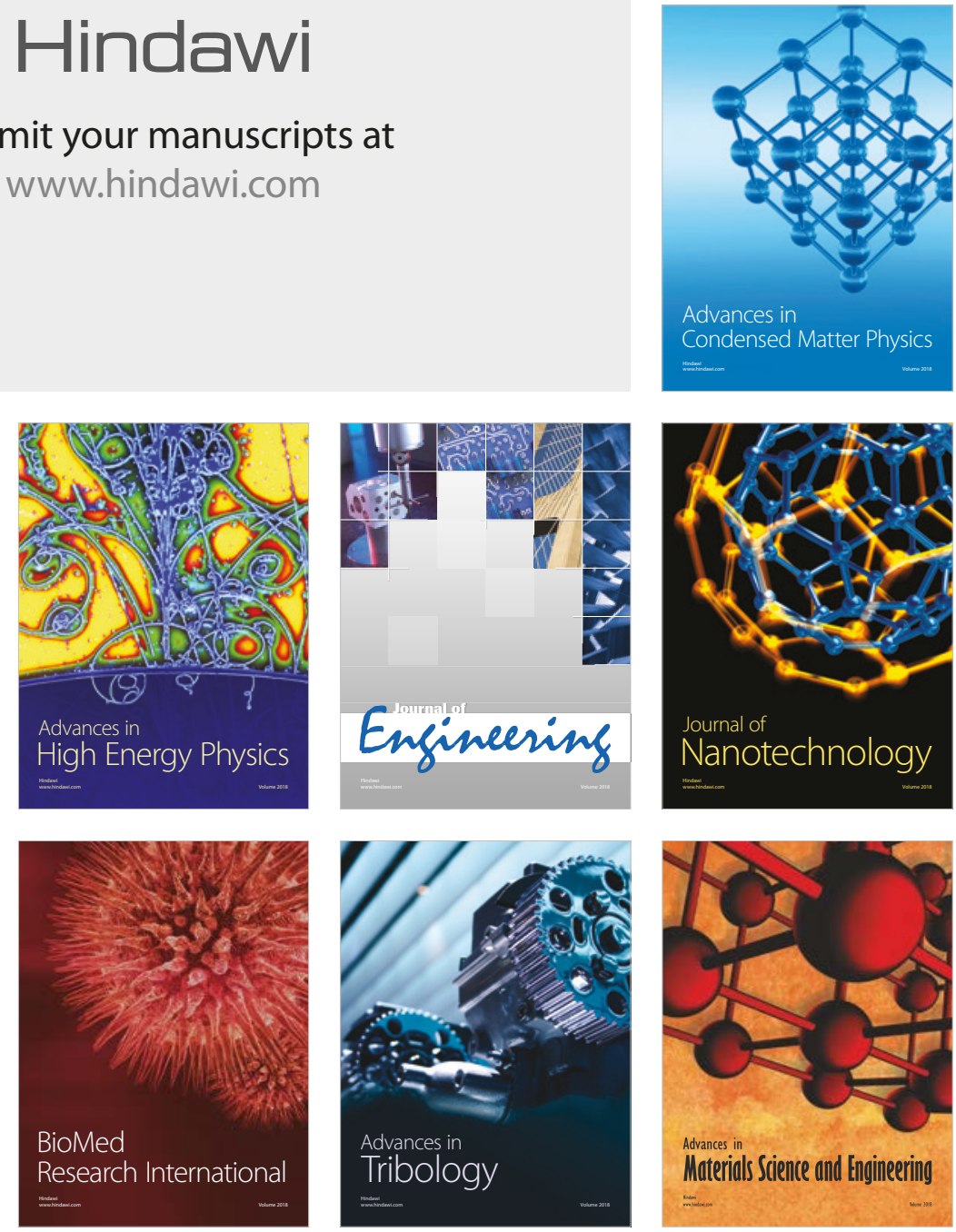